\title{
Dolutegravir Inhibition of Matrix Metalloproteinases Affects Mouse Neurodevelopment
}

\author{
Aditya N. Bade $^{1} \mathbb{D} \cdot$ JoEllyn M. McMillan ${ }^{1} \cdot$ Yutong Liu ${ }^{1,2} \cdot$ Benson J. Edagwa $^{1} \cdot$ Howard E. Gendelman $^{1,3} \mathbb{D}$
}

Received: 14 June 2021 / Accepted: 25 July 2021 / Published online: 14 August 2021

(c) The Author(s) 2021

\begin{abstract}
Dolutegravir (DTG) is a first-line antiretroviral drug (ARV) used in combination therapy for the treatment of human immunodeficiency virus type-1 (HIV-1) infection. The drug is effective, safe, and well tolerated. Nonetheless, concerns have recently emerged for its usage in pregnant women or those of child-bearing age. Notably, DTG-based ARV regimens have been linked to birth defects seen as a consequence of periconceptional usages. To this end, uncovering an underlying mechanism for DTG-associated adverse fetal development outcomes has gained clinical and basic research interest. We now report that DTG inhibits matrix metalloproteinases (MMPs) activities that could affect fetal neurodevelopment. DTG is a broad-spectrum MMPs inhibitor and binds to $\mathrm{Zn}^{++}$at the enzyme's catalytic domain. Studies performed in pregnant mice show that DTG readily reaches the fetal central nervous system during gestation and inhibits MMP activity. Postnatal screenings of brain health in mice pups identified neuroinflammation and neuronal impairment. These abnormalities persist as a consequence of in utero DTG exposure. We conclude that DTG inhibition of MMPs activities during gestation has the potential to affect prenatal and postnatal neurodevelopment.
\end{abstract}

Keywords Dolutegravir $\cdot$ HIV-1 $\cdot$ Antiretroviral drug $\cdot$ Pregnancy outcomes $\cdot$ Matrix metalloproteinases $\cdot$

Neurodevelopment

\section{Introduction}

The World Health Organization updated guidance recommends continuation or initiation of antiretroviral therapy (ART) in all pregnant and breastfeeding women living with human immunodeficiency virus type-1 (HIV-1) infection [1]. Around 1.3 million HIV-1-infected pregnant women worldwide give birth each year [2]. With increased numbers of infected pregnant women receiving ART, over a million HIV-1-exposed but uninfected (HEU) children are

Aditya N. Bade

aditya.bade@unmc.edu

$\triangle$ Howard E. Gendelman

hegendel@unmc.edu

1 Department of Pharmacology and Experimental Neuroscience, University of Nebraska Medical Center, Omaha, NE 68198-5800, USA

2 Department of Radiology, University of Nebraska Medical Center, Omaha, NE 68198, USA

3 Department of Pharmaceutical Sciences, University of Nebraska Medical Center, Omaha, NE 68198, USA born each year $[2,3]$. This results in potential exposures of fetuses to antiretroviral drugs (ARVs) during development. Importantly, emerging data demonstrates that HEU children have inferior health outcomes compared to their HIV-1-unexposed counterparts [4]. This highlights an immediate need to identify any ARV or class thereof associated with adverse pregnancy outcomes. There is a need to define any altered prenatal and postnatal developmental outcomes after ARV exposures and elucidate underlying mechanisms.

Dolutegravir (DTG) is currently recommended as a part of first, second, or salvage regimens for HIV-1-infected patients, in both resource-rich and resource-limited countries (RRCs and RLCs) [1,5]. This is due to its high potency and genetic barriers to drug resistance [6-8]. Nonetheless, in recent years, concerns for the usage of DTG-based regimens by pregnant women or women of child-bearing age emerged based on apparent increases in fetal abnormalities $[2,9,10]$. In 2018, the interim analysis of the Tsepamo birth surveillance study in Botswana reported neural tube defects (NTDs) at eight times higher rates in babies born to mothers who received DTG periconceptionally compared to those who had taken other ARVs [9]. Extended surveillance in 
Botswana showed lower risk of NTDs, yet the risk was 2-3 times higher than other ARTs at conception [10]. In addition, DTG-associated fetal defects were reported when pregnant mice were given the drug at therapeutic levels [11]. Both clinical and preclinical studies observed the risk of NTD's following in utero DTG exposure and stressed the importance of identifying unknown potential adverse drug effects (ADEs) [9-11]. These include any injuries resulting from in utero DTG exposures, including biological, physiological, metabolic, or functional harm to the fetal central nervous system (CNS), particularly in babies born without structural, brain or spinal cord, malformations [12, 13]. Recently, the Surveillance Monitoring for ART Toxicities (SMARTT), an observational study, reported associations between in utero DTG exposures and neurologic abnormalities in newborns and during development [2]. These studies underscored the importance for identifying both the neurologic abnormalities and the mechanisms for how they could occur following in utero DTG exposure.

DTG is an integrase strand transfer inhibitor (INSTI) that blocks the action of the viral integrase enzyme, which is responsible for the insertion of the viral genome into the host cellular DNA. It possesses a metal-binding pharmacophore (MBP, also referred as a metal-binding group, MBG) for engagement with active metal ion $\left(\mathrm{Mg}^{++}\right)$sites in the HIV-1 integrase [14]. With a metal chelating motif in the chemical structure, DTG possesses potential to interact with other metalloenzymes that are critical for normal biological activities, including cell proliferation, differentiation, signaling, nucleic acid modification, and protein degradation. Out of all metalloenzymes, matrix metalloproteinases (MMPs) are a class of $\mathrm{Zn}^{++}$-dependent enzymes that are essential during CNS developmental processes such as axonal growth and guidance, synaptic development and plasticity, myelinogenesis, and angiogenesis [15-26]. Dysregulation of MMPs can cause detrimental effect on neurodevelopment and normal functioning. Thus, we hypothesized that DTG inhibition of MMPs activities by chelating $\mathrm{Zn}^{++}$at the catalytic domain during gestation can certainly affect neurodevelopment.

To each of these ends, the findings contained in the current report demonstrate, for the first time, a novel, yet, previously undisclosed pathway for DTG-associated developmental neurotoxicity that follows in utero exposure in mice. The identified pathway was linked to DTG inhibition of MMPs activities. Interestingly, DTG was found to be a broad-spectrum inhibitor of MMPs. In mice, DTG exposure to the developing embryo CNS during gestation inhibited MMPs activities. Further postnatal evaluation of brain health in mice pups following DTG exposures identified neuroinflammation and consequent neuronal damage. These data demonstrate an association between DTG dysregulation of MMPs activity during gestation and consequent neurotoxicity. We conclude that DTG inhibition of MMPs activities during gestation can affect neurodevelopment in mice warranting continued observations in humans.

\section{Methods}

\section{Gelatin Zymography}

The gelatin zymography assay was performed to determine MMP-9 and MMP-2 activity following treatment of THP-1 cells with DTG. THP-1 cells were plated in 12-well plates at a density of $1 \times 10^{6}$ cells per well. First, THP- 1 were treated with phorbol-12-myristate-13-acetate (PMA) for $24 \mathrm{~h}$ to promote the differentiation of cells into macrophages and stimulate MMP secretion. Following 24-h treatment with PMA, cells were treated with DTG $(1,10$, or $100 \mu \mathrm{M})$ or vehicle (control) for $18 \mathrm{~h}$. For each treatment, biological triplicate samples were utilized. Following treatment, cell medium was collected from each well and centrifuged at $800 \times \mathrm{g}$ for $10 \mathrm{~min}$ at $4{ }^{\circ} \mathrm{C}$ to remove any cell debris. Collected samples were stored at $-80^{\circ} \mathrm{C}$ for further analysis. A $10 \%$ SDS-polyacrylamide gel containing $0.1 \%$ gelatin was loaded with $3 \mu \mathrm{g}$ of protein from cell medium for gelatin zymography. In parallel, second 10\% SDS-polyacrylamide gel was used to assess equal protein loading. In addition, recombinant human MMP-2 and MMP-9 (10 ng each) were loaded as standards (EMD Millipore, Burlington, MA). Gel ran at $60 \mathrm{~V}$ until the loading dye reached the bottom of the gel. After the run, the gelatin gel was washed with water for $15 \mathrm{~min}$ and incubated in renaturation buffer [2.5\% (v/v) Triton X-100 in Milli-Q water] for $60 \mathrm{~min}$ at room temperature. The renaturation buffer was replaced with a fresh renaturation buffer at the interval of $30 \mathrm{~min}$. Later, the gel was incubated in developing buffer $(50 \mathrm{mM}$ Tris- $\mathrm{HCl}, \mathrm{pH}$ 7.5, $5 \mathrm{mM} \mathrm{CaCl}_{2}, 0.2 \mathrm{M} \mathrm{NaCl}$, and $0.02 \%$ Brij-35) for $48 \mathrm{~h}$ at $37{ }^{\circ} \mathrm{C}$ in an incubator shaker (Innova 42, New Brunswick Scientific, Edison, NJ). The gel was later washed with water for $15 \mathrm{~min}$ and then stained with $0.2 \%$ Coomassie Brilliant Blue R-250 (BIO-RAD, Hercules, CA) for $1 \mathrm{~h}$. After staining, the gel was washed with water for 15 min followed by washing with destaining solution (BIO-RAD, Hercules, CA) for $30 \mathrm{~min}$. The gel was washed one more time for $15 \mathrm{~min}$ with water to remove any distaining solution. Finally, the stained gel was imaged by iBright 750 Imaging Systems (Invitrogen, Carlsbad, CA). Relative activity of MMPs was measured by quantitating band density by ImageJ software and normalized with respective standard.

\section{Cytotoxicity Measurements}

Cellular viability following treatment with DTG was evaluated by 3-(4,5-dimethylthiazol-2-yl)-2,5-diphenyltetrazolium bromide (MTT) assay. THP-1 cells were plated in 96-well 
plates at a density of $0.08 \times 10^{6}$ cells per well. Cells were treated with 1,10 , or $100 \mu \mathrm{M}$ DTG for $18 \mathrm{~h}$ in presence of PMA to determine the cellular toxicity. Vehicle-treated cells were used as controls. For each treatment, twelve samples were utilized. Cells were washed with PBS and incubated with $100 \mu \mathrm{L} /$ well of MTT solution $(5 \mathrm{mg} / \mathrm{mL})$ for $45 \mathrm{~min}$ at $37{ }^{\circ} \mathrm{C}$. After incubation, MTT solution was removed, and DMSO $(200 \mu \mathrm{L})$ was added to each well. Absorbance was measured at $490 \mathrm{~nm}$ on a Molecular Devices SpectraMax M3 plate reader with SoftMax Pro 6.2 software (Sunnyvale, CA). Absorbance was compared to that of control cells to determine cytotoxicity.

\section{Fluorometric Substrate Assays}

MMP inhibitor profiling kit from Enzo life sciences (BMLAK308, Farmingdale, NY) was utilized to assess quantitative inhibition profile of DTG against ten different MMPs. Kit contained a panel of ten MMPs and a quenched fluorogenic substrate OMNIMMP® RED. Composition of a quenched fluorogenic substrate was TQ3-GABA-Pro-Cha-Abu-SmcHis-Ala-Dab(6'-TAMRA)-Ala-Lys-NH2 [TQ3 = quencher; GABA $=4$-aminobutyric acid; Cha $=$ L-cyclohexylalanine; $\mathrm{Abu}=2$-aminobutyric acid; Smc $=$ S-methyl-L-cysteine; $\mathrm{Dab}=2,4$-diaminobutyric acid; 6'-TAMRA =6'-tetramethylrhodamine]. Experiment was performed as per instructions provided in the manufacturer's manual. The assays were performed in a 96-well, black, flat, microplate format. The compound NNGH was provided as a prototypic control inhibitor. Briefly, DTG at five different concentrations $(0.1,1,10,100$, and $1000 \mu \mathrm{M})$ and $\mathrm{NNGH}$ were incubated with each MMP at $37^{\circ} \mathrm{C}$ for $60 \mathrm{~min}$. Untreated MMPs were used as control. The experiment was performed in biological triplicates. After 60-min incubation, fluorogenic substrate OMNIMMP® RED was added to each reaction/well to start the reaction. The plate was continuously read at Ex/ $\mathrm{Em}=545 / 576 \mathrm{~nm}$ (cutoff at $570 \mathrm{~nm}$ ) for $30 \mathrm{~min}$ with 1-min time intervals at constant temperature, $37^{\circ} \mathrm{C}$, using Molecular Devices SpectraMax M3 plate reader with SoftMax Pro 6.2 software. The half maximal inhibitory concentration $\left(\mathrm{IC}_{50}\right)$ value of DTG for each enzyme was calculated using four-parameter curve fit using R software package.

\section{Molecular Docking}

Homology models of MMP-8, MMP-9, MMP-14, and MMP-19 were generated on a template of MMP-2 (PDB ID: 1HOV) using the Homology Modeling module of the YASARA Structure [27] program package. The models of MMP-9, MMP-14, and MMP-19 have Z-scores less than -2.0 and were subjected to 500 ns molecular dynamics simulations to refine their structures. The Schrodinger software suite release 2020-4 (New York, NY) was used for all molecular dynamics simulations and molecular docking calculations. All molecules were parametrized using the OPLS3e [28] force field. Each homology model was placed in an orthorhombic box of TIP4P water with periodic boundaries at least $10 \AA$ from any solute molecule. The simulation cells were neutralized with the addition of $\mathrm{Na}^{+}$or $\mathrm{Cl}^{-}$ions as appropriate. The systems were relaxed following the standard protocol as implemented in the Schrodinger suite. Production molecular dynamics were run for $500 \mathrm{~ns}$ with default settings. The representative structure of the largest cluster from each simulation was chosen for docking calculations. Induced-fit binding as implemented in Schrodinger was used with default settings, except that the high-accuracy XP mode was chosen for the Glide docking steps. All ranked poses were required to have at least one bond with the active site zinc ion; other poses were not considered.

\section{Animals}

For all animal experiments, $\mathrm{C} 3 \mathrm{H} / \mathrm{HeJ}(10-12$ weeks of age, male and female) were purchased from the Jackson Laboratory (Bar Harbor, ME), and were housed in microisolator cages containing autoclaved corncob bedding, and maintained on a 12-h light-dark cycle in climate-controlled laboratory animal facilities approved by the University of Nebraska Medical Center Institutional Animal Care and Use Committee (IACUC). Mice were given free access to irradiated rodent feed (TD. 180,911, Envigo Teklad diet, Madison, WI) and sterile water. Animals were acclimated to the environment for approximately $7-14$ days to determine that they were healthy based on observed behavior and weight gain. A female was placed with a male overnight for the purpose of timed matings. The following morning males were removed from the cages and positive vaginal plugs were identified. Females exhibiting vaginal plugs were weighed and were randomly distributed to treatment (DTG) or control group. Male mice did not receive any drug/chemical exposure. The time of conception was considered to be midnight on the evening of the mating. Treatment of plugged females was started at the morning of the day of plug detection (gestation day (GD) 0.5).

\section{PK and BD of DTG During Pregnancy}

Pharmacokinetic (PK) and biodistribution (BD) profiles of DTG were determined in pregnant female $\mathrm{C} 3 \mathrm{H} / \mathrm{HeJ}$ mice (10-12 weeks old). Pregnant mice were administered DTG daily at a dose of $50 \mathrm{mg} / \mathrm{kg}$. DTG solution in dimethylsulfoxide:Solutol@:50 mM N-methylglucamine in $3 \%$ mannitol (1:1:8, v:w:v) was administered by oral gavage throughout the entire gestational period. Drug administration was started at the day of plug detection (GD 0.5) and continued up to the day of birth of pups. Blood samples were 
collected from dams into heparinized tubes by cheek puncture (submandibular vein) using a 5-mm lancet (MEDIpoint, Inc., Mineola, NY) at GD 8.5 and 16.5 and postnatal days (PND) 4, 12, and 21 for plasma collection. Collected blood samples were centrifuged at $2000 \times \mathrm{g}$ for $8 \mathrm{~min}$ for plasma collection and quantitation of plasma DTG concentrations. DTG concentrations were also quantitated in harvested placental tissue at GD 16.5. In addition, biodistribution of DTG to fetal brain tissue was determined at GD 16.5 and PND 4. DTG levels were quantitated in plasma, and tissue homogenates by ultraperformance liquid chromatographytandem mass spectrometry (UPLC-MS/MS) according to previously published protocols [29]. Each sample (plasma or tissue) evaluated for DTG levels was randomly selected from distinct litters.

\section{Embryo Phenotype Assessments}

Effect of DTG exposure during gestation on embryo development was evaluated. Pregnant $\mathrm{C} 3 \mathrm{H} / \mathrm{HeJ}$ mice were administered daily with DTG solution at a dose of $50 \mathrm{mg} / \mathrm{kg}$ or vehicle [dimethylsulfoxide:Solutol@:50 mM N-methylglucamine in $3 \%$ mannitol $(1: 1: 8, \mathrm{v}: \mathrm{w}: \mathrm{v})]$ by oral gavage. DTG or vehicle was administered by oral gavage from GD 0.5 to GD 15.5. Pregnant dams were randomly assigned to DTG or vehicle (control) group. Weight gain in dams was measured on GD 0.5, 5.5, 10.5, and 15.5. At GD 16.5, dams were humanely euthanized, and embryos and placenta were harvested. Embryos were evaluated for NTDs. At the time of harvest, the total number of implants (litter size, resorption rates, or viable embryos) was recorded for each pregnancy. Further, whole brain tissues from normal viable embryos were isolated and processed for examination of MMP expression and activity.

\section{MMP Activity Measurements in Embryonic Brain}

Broad-spectrum MMP activity was measured in whole brain tissue homogenates of normal, viable embryos (GD 16.5) using a quenched fluorogenic substrate, OMNIMMP® RED (BML-P277-0100, Enzo Life Sciences). Whole brain tissues were isolated from randomly selected embryos from different dams for both DTG and control groups. Tissues were homogenized in NP-40 lysis buffer using a Qiagen TissueLyzer II (Valencia, CA). Tissue lysates were centrifuged at $16,000 \mathrm{~g}$ at $4{ }^{\circ} \mathrm{C}$ for $20 \mathrm{~min}$ and supernatants were collected. Total protein levels in each sample were quantitated using Pierce ${ }^{\mathrm{TM}}$ BCA Protein Assay Kit (Thermo Fisher Scientific, Waltham, MA). The assays were performed in a 96-well, black, flat, microplate format. Fifty micrograms of protein for each sample was incubated with buffer (BMLKI175-0020, Enzo Life Sciences) at $37{ }^{\circ} \mathrm{C}$ for $60 \mathrm{~min}$. Each sample was platted in duplicates. Later, reaction was started by adding fluorogenic substrate. Plate was read at similar instructions mentioned above for fluorometric substrate assay. Ilomastat (GM6001; broad-spectrum MMP inhibitor, ab120845, abcam) was added to randomly selected protein samples in additional wells at $20 \mu \mathrm{M}$ concentration as an assay control.

\section{MMP Expression}

At GD 16.5, embryo whole brain tissues were isolated and homogenized in lysis buffer. Whole brain tissue homogenates were analyzed for expression of MMP-2, 9, and 14 using Western blot assay. Six pups were randomly selected from 6 different dams for both DTG- and vehicle-treated groups. Tissue lysates were centrifuged at $16,000 \times \mathrm{g}$ at $4{ }^{\circ} \mathrm{C}$ for 20 min and supernatants were collected. Total protein levels in each sample were quantitated using Pierce ${ }^{\mathrm{TM}}$ BCA Protein Assay Kit (Thermo Fisher Scientific). Fifteen micrograms of protein for each sample was ran on $10 \%$ SDS-polyacrylamide gel. Proteins were transferred to activated PVDF membrane. Membranes were blocked with 5\% non-fat milk (BIO-RAD) for $1 \mathrm{~h}$ and incubated with individual primary antibody overnight at $4{ }^{\circ} \mathrm{C}$ on a shaker. The primary antibodies used were rabbit monoclonal anti-MMP-2 (ab181286, abcam, Cambridge, MA), rabbit polyclonal antiMMP-9 (ab38898, abcam), rabbit monoclonal anti-MMP-14 (ab51074, abcam), rabbit monoclonal GAPDH (Cell Signaling Technology, Inc., Danvers, MA), and mouse monoclonal $\beta$-actin (Santa Cruz Biotechnology, Dallas, TX). All the primary antibodies were used at 1:2000 dilution. After overnight incubation with primary antibody, the membranes were washed with Tris-buffered saline with $0.1 \%$ Tween ${ }^{\circledR}$ 20 detergent (TBST) three times (5 min each wash). Membranes were then incubated with secondary antibody for $1 \mathrm{~h}$ at room temperature. The secondary antibodies used were goat anti-rabbit IgG H\&L (HRP) (ab205718, abcam) and goat anti-mouse IgG H\&L (HRP) (ab205719, abcam). For secondary antibodies, 1:10,000 dilutions were used. Blots were developed using SuperSignal ${ }^{\mathrm{TM}}$ West Femto Maximum Sensitivity Substrate (Thermo Fisher Scientific) and iBright 750 Imaging System. Band intensity was analyzed using ImageJ software.

\section{Diffusion Tensor Imaging}

In vivo bioimaging (diffusion tensor imaging (DTI) and magnetic resonance spectroscopy $\left({ }^{1} \mathrm{H}\right.$ MRS)) was performed using a 7 Tesla/16 cm Bruker PharmaScan or a 7 Tesla $21 \mathrm{~cm}$ Bruker Biospec (Karlsure, Germany) MRI/ MRS system. At PND 28-34, DTI was performed on live mice pups to determine microstructural changes. Animals from both DTG- and vehicle-treated (control) groups were scanned. Pups (male and female) were randomly selected 
from each dam. As described in our previous work [30], a 4-segment echo planar imaging (EPI) readout with a balanced, rotationally invariant and alternating polarity icosahedral scheme (12 directions) and $b$ value $=800 \mathrm{~s} / \mathrm{mm}^{2}$ were utilized. Diffusion Toolkit (http://trackvis.org/dtk/) was used to calculate DTI metrics, fractional anisotropy (FA). Region of interest (ROI) analysis was performed to measure DTI metrics on hippocampus (HI), cortex (CT), striatum (ST), thalamus (TH), hypothalamus (HY), and cerebellum (CE).

\section{Magnetic Resonance Spectroscopy}

After DTI measurements, the same animals were scanned by ${ }^{1} \mathrm{H}$ MRS to measure metabolite concentrations. $N$-Acetylaspartate (NAA), total choline (tCho), and total creatine (tCre) were measured in HI region. Animals from both groups, DTG and control, were scanned. SemiLASER localization with timing parameters $(\mathrm{TE} / \mathrm{TR}=40 / 4000 \mathrm{~ms}, 576$ averages, 2048 points) was used to obtain MRS data [31]. Voxel was located on HI. All first- and second-order shim terms were automatically adjusted using MAPSHIM ${ }^{\circledR}$ (Bruker, Billerica, MA). A final shim performed manually, if necessary, to achieve a water line width of 10-15 Hz. The water signal was suppressed by variable power radiofrequency (RF) pulses with optimized relaxation delays (VAPOR) [32]. MRS data were quantified using LCModel (LCMODEL Inc., CA). Results were expressed as a percentage of the sum of all 3 metabolites as a semi-quantitative method for reporting metabolite concentrations in institutional units (I.U.). Glycerophosphocholine and phosphocholine were added and reported as total choline-containing compounds.

\section{Next-Generation Sequencing}

After MRI imaging, animals were humanely euthanized and brain regions were isolated. Brain tissues were flash frozen in liquid nitrogen and stored in $-80^{\circ} \mathrm{C}$. Tissue RNA was isolated from $\mathrm{HI}$ region using RNeasy Mini Kit (QIAGEN, Germantown, MD). HI region from 4 randomly selected pups from 4 different dams for each group (DTG-treated and vehicle-treated) was used to isolate RNA. Nucleic acid integrity was assessed, and the RNA samples were deep sequenced using $100 \mathrm{bp} / \mathrm{read}$ and $\leq 40$ million reads/sample using an Illumina HiSeq 2500 Sequence Analyzer (Illumina, Inc., San Diego, CA, USA). The original fastq format reads were merged and trimmed using the fqtrim tool (https:// ccb.jhu.edu/software/fqtrim) to remove adapters, terminal unknown bases (Ns), and low-quality $3^{\prime}$ regions (Phred score $<30$ ). Quality was assessed for each trimmed file with FASTQC for high-throughput sequence data. The trimmed fastq files were processed utilizing STAR [33] as the aligner and RSEM [34] as the tool for annotation and quantification at both gene and isoform levels. The trimmed fastq files were mapped to the mouse reference genome according to the corresponding sample species. The gene and transcript abundance were measured as transcripts per kilobase million (TPM) values. TPM was calculated by normalizing the gene length, followed by the sequencing depth to make easier comparison of the proportion of reads that mapped to a gene in each sample. The identified set of genes was then used to examine the differential expression of various genes between the sample groups in the R statistical software environment with packages from Bioconductor and to identify pathways using Ingenuity pathway analysis (https://www.qiagenbioinformatics.com). Comparison analysis was performed between DTG-treated and vehicle-treated (control) samples. We identified differentially expressed genes and associated pathways with $\log _{2}$ (fold change) $<0.5$ and $>-0.5$ and $p$ values $<0.05$. The top ranking upregulated and downregulated genes were selected to plot the graphs.

\section{Statistical Analysis}

Statistical analyses were conducted using GraphPad Prism 7.0 software (La Jolla, CA). Data from in vitro studies were expressed as mean \pm standard error of the mean (SEM) with a minimum of 3 biological replicates. Results from in vivo studies were expressed as mean \pm SEM with a minimum of 4 biological replicates. For comparisons between two groups, $t$ test (two-tailed) with Welch's correction was employed. A one-way ANOVA followed by Dunnett's test was used to compare three or more groups. Statistical significances were denoted as follows: ${ }^{\#} p<0.1, * p<0.05, * * p<0.01$, $* * * p<0.001, * * * * p<0.0001$.

\section{Study Approvals}

All animal studies were approved by the University of Nebraska Medical Center Institutional Animal Care and Use Committee (IACUC) in accordance with the standards incorporated in the Guide for the Care and Use of Laboratory Animals (National Research Council of the National Academies, 2011).

\section{Results}

\section{DTG Is a Broad-Spectrum MMPs Inhibitor}

To affirm that DTG inhibits MMP activity, two commonly used assays to study MMP activity and their inhibitors were performed. These included gelatin zymography and fluorometric substrate assays [35, 36]. For gelatin zymography, cell culture of the monocyte THP-1 cell line was employed. Phorbol-12-myristate-13-acetate (PMA) was used to differentiate THP-1 cells into macrophage-like cells and to 
induce MMP secretion [37, 38]. Herein, PMA-stimulated THP-1 cells were treated with escalating DTG concentrations $(1,10$, or $100 \mu \mathrm{M})$ for $18 \mathrm{~h}$ in serum-free culture medium. To determine the proteolytic activity of MMPs 2 and 9 (gelatinases), equal amount of protein $(3 \mu \mathrm{g})$ from cell culture medium was loaded on SDS-PAGE containing gelatin. Gel area digested by both MMPs was visualized with Coomassie blue (Fig. 1A). Pro and active forms of both enzymes were confirmed with respective standards, human recombinant MMP-2 and MMP-9 (lanes 1 and 2; Fig. 1A).
Fig. 1 DTG inhibition of MMPs. A Gelatin zymogram. Activity of MMP-2 and MMP-9 was evaluated in serum-free medium of THP-1 cells following treatment with DTG $(1,10$, or $100 \mu \mathrm{M})$. Vehicle-treated cells were used as control. Human recombinant enzymes were used as standards. B Relative activity of MMP-9 or MMP-2 was measured and normalized with respective standard. A one-way ANOVA followed by Dunnett's test was used to compare activity of individual MMP between each treatment concentration and untreated control $(* * p<0.01$, $* * * p<0.001)$. C Fluorometric substrate assay. Inhibition profile of DTG $(0.1,1,10,100$, and $1000 \mu \mathrm{M})$ was determined against ten human recombinant MMP enzymes. $\mathbf{D}$ IC $_{50}$ values for DTG against each MMP were calculated from doseresponse curve (fluorometric substrate assay) using fourparameter hill-slope model. For both assays, data are expressed as the mean $\pm \operatorname{SEM}, N=3$ biological replicates. Experiments were repeated independently three times with equivalent results
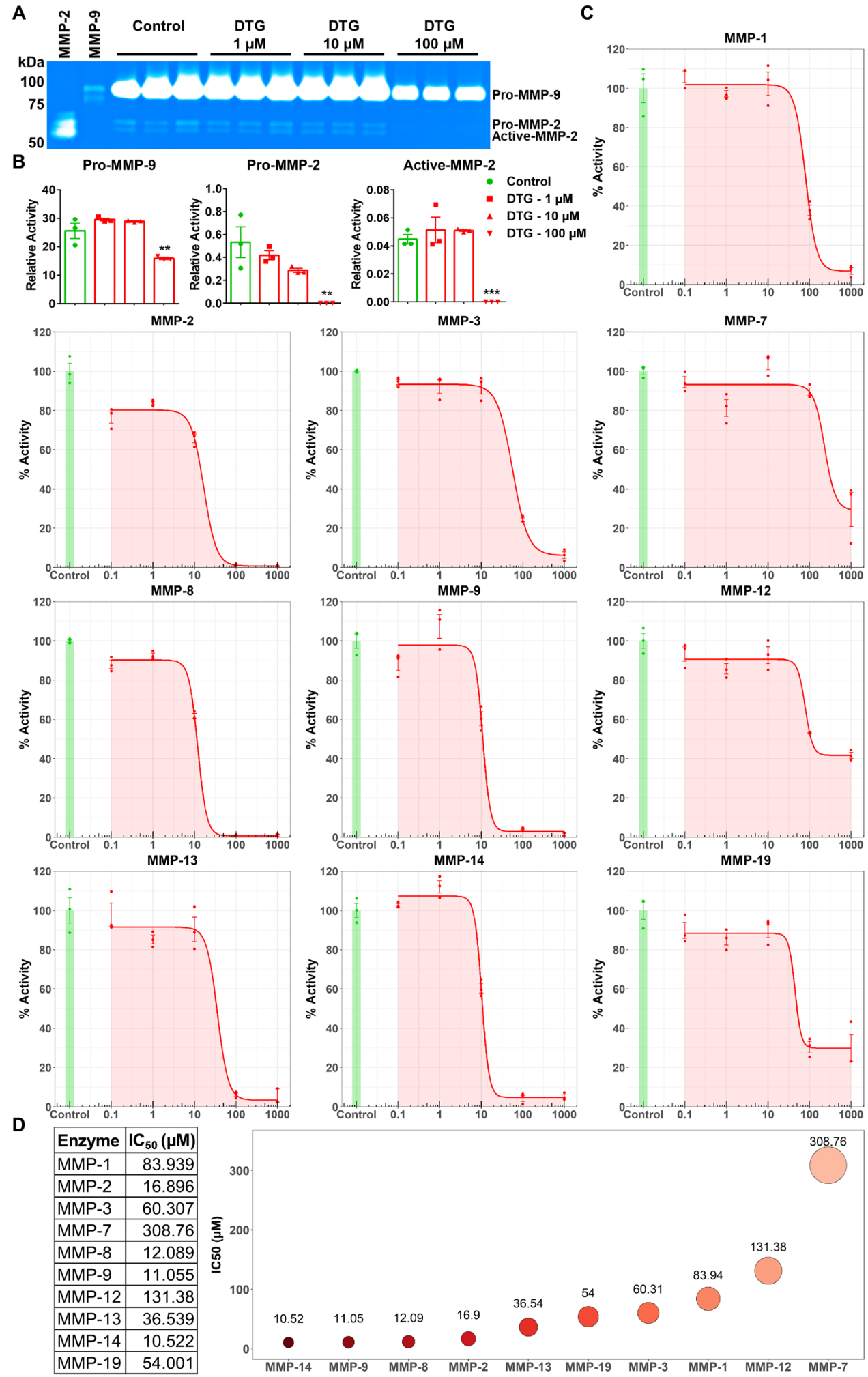
Decrease in activity of MMP-2 and 9 was observed following DTG treatment compared to vehicle-treated controls on gelatin zymogram (Fig. 1A). Relative activity of both pro and active forms of MMP-2 and pro form of MMP-9 was significantly decreased by DTG treatment at $100 \mu \mathrm{M}$ concentration compared to controls (Fig. 1B). Cellular vitality assessed in THP-1 cells by the 3-(4,5-dimethylthiazol-2-yl)2,5-diphenyltetrazolium bromide (MTT) assay showed no DTG-induced cytotoxicity at 1,10 , or $100 \mu \mathrm{M}$ drug concentration (Supplementary Fig. 1). After confirmation from the standard gelatin zymography assay that DTG inhibits activity of MMP-2 and MMP-9, a fluorometric substrate assay was performed to assess quantitative inhibition profile of DTG against different MMPs (Fig. 1C). Ten MMPs included in assay can affect embryonic development and represent each of the MMP subfamilies [15-26]. Dosedependent enzymatic activity inhibition over time was measured. Resulting reaction rates were normalized as percentage of the respective untreated control and plotted against drug concentrations (Fig. 1C). The half maximal inhibitory concentration $\left(\mathrm{IC}_{50}\right)$ for each enzyme was calculated using a four-parameter curve fit (Fig. 1D). DTG inhibited activity of all ten MMP enzymes at different extent. $\mathrm{IC}_{50}$ values for DTG inhibition of enzyme's activity for MMP-2 $\left(\mathrm{IC}_{50}: 16.89 \mu \mathrm{M}\right), \mathrm{MMP}-8\left(\mathrm{IC}_{50}: 12.08 \mu \mathrm{M}\right)$, MMP-9 ( $\mathrm{IC}_{50}$ : $11.05 \mu \mathrm{M}$ ), and MMP-14 ( $\mathrm{IC}_{50}: 10.52 \mu \mathrm{M}$ ) (Fig. 1D) were determined. Other $\mathrm{IC}_{50}$ values of DTG were 83.93, 60.30, $308.76,131.37,36.53$, and 54.0 $\mu \mathrm{M}$ for MMP-1, 3, 7, 12, 13 , and 19, respectively. To visualize the extent of inhibition among MMPs, the sequence of $\mathrm{IC}_{50}$ values for DTG inhibition of MMPs is shown in a bubble chart (Fig. 1D). This chart starts with the lowest $\mathrm{IC}_{50}$ value (MMP-14; $\mathrm{IC}_{50}$ : $10.52 \mu \mathrm{M}$; dark red color) and increases to higher $\mathrm{IC}_{50}$ values with respective MMPs, which are presented in lighter red color shades (Fig. 1D). These results were further validated in comparison to doxycycline which is the only US Food and Drug Administration (FDA)-approved broad-spectrum MMPs inhibitor [39] (Supplementary Fig. 2). At $20 \mu \mathrm{M}$ concentration, DTG had higher inhibitory effect on MMP-2, $8,9,13$, and 14 compared to doxycycline. Altogether, gelatin zymography and fluorometric substrate assays demonstrated that DTG is a broad-spectrum MMPs inhibitor.

\section{DTG Binds to $\mathrm{Zn}^{++}$at Catalytic Domain of MMP to Inhibit the Enzyme's Activity}

With the establishment that DTG inhibits MMP activity, computational molecular docking evaluations were completed using Schrodinger's software. These tests were performed to identify the mechanism through which DTG interacts with catalytic domain of MMPs. MMPs are part of a family of structurally related $\mathrm{Zn}^{++}$-dependent endopeptidases [39]. As DTG possesses a prominent MBP for binding to the metal ions [14], we hypothesized that DTG inhibits activity of MMP by binding to $\mathrm{Zn}^{++}$at the catalytic domain. Since DTG inhibits MMP-2, 8, 9, 14, and 19 to a higher extent (low $\mathrm{IC}_{50}$ values, Fig. 1C, D), these enzymes were used for DTG-MMP mechanistic studies. Herein, induced fit docking used a combination of the Glide and Prime programs in the Schrodinger suite. All docking scores used the highest accuracy Glide XP mode. A representative 3D image of MMP-2 catalytic domain with $\mathrm{Zn}^{++}$ion (bright green ball) is shown in Fig. 2A. Chemical structures of DTG with ligand interaction sites (numbered and colored) are shown in Fig. 2B. Docking simulation of DTG into individual MMP showed highest binding energy of $-6.45,-8.33,-9.43$, 9.04 , or $-7.13 \mathrm{kcal} / \mathrm{mol}$ for MMP-2, 8, 9, 14, or 19 , respectively (Fig. 2C). DTG formed a metal coordination complex with $\mathrm{Zn}^{++}$in the catalytic domain of all tested MMPs (Fig. 2D-H). Metal coordination with $\mathrm{Zn}^{++}$occurred at $\mathrm{Zn}$ 166, 469, 709, 584, and 510 of MMP-2, 8, 9, 14, and 19 respectively (Fig. 2D-H). Other interactions that occurred were hydrogen bonding and pi stacking. Specifically, pi stacking occurred at histidine 120 amino acid of MMP-2, histidine 217 amino acid of MMP-8, and histidine 239 amino acid of MMP-14 (Fig. 2D-H). The hydrogen bond interactions occurred at alanine 84 amino acid of MMP-2; the three hydrogen bond interactions occurred at leucine 180 , alanine 181, and asparagine 170 amino acid residues of MMP-8; the four hydrogen bond interactions occurred at glycine 186, tyrosine 423 , proline 421 , and leucine 188 amino acid residues of MMP-9; the hydrogen bond interactions occurred at alanine 258 amino acid of MMP-14, and the two hydrogen bond interactions occurred at alanine 231 and glutamate 235 amino acid residues of MMP-19 (Fig. 2D-H). The distances of all the enzyme-ligand bonds are shown in the respective enzyme interaction tables (Fig. 2D-H). Overall, the binding energies from the docking simulation validated $\mathrm{IC}_{50}$ values (Fig. 1C, D). Computational molecular docking assessments confirmed that DTG is a broad-spectrum inhibitor, and it inhibits MMPs activities by chelating $\mathrm{Zn}^{++}$at the catalytic domain.

Further, we completed preliminary molecular docking assessments for other drugs of INSTIs to determine whether interaction with the $\mathrm{Zn}^{++}$at catalytic domain of MMPs is a class effect. We assessed molecular docking of cabotegravir (CAB), bictegravir (BIC), and raltegravir (RAL) on MMP-2 and 14. Notably, all three INSTIs (CAB, BIC, and RAL) formed receptor interactions with $\mathrm{Zn}^{++}$in the catalytic domain of both MMPs (Supplementary Fig. 3). RAL formed two metal and one cation pi interactions with $\mathrm{Zn}^{++}$ at $\mathrm{Zn} 166$ MMP-2 and formed one metal and one cation pi interactions at Zn 584 of MMP-14 (Supplementary Fig. 3A). BIC formed two metal and one salt bridge interactions with $\mathrm{Zn}^{++}$at $\mathrm{Zn} 166$ MMP-2 and formed two metal and one salt bridge interactions at Zn 584 of MMP-14 (Supplementary 
A

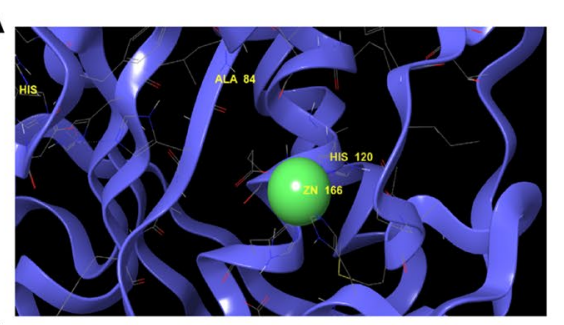

D

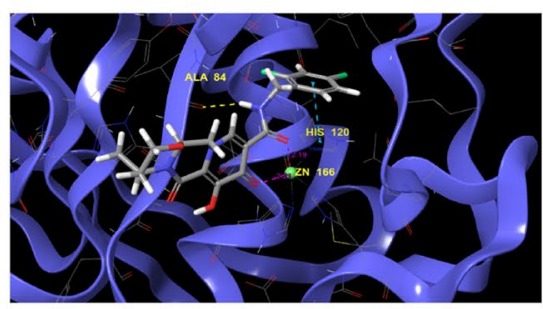

$\mathrm{E}$
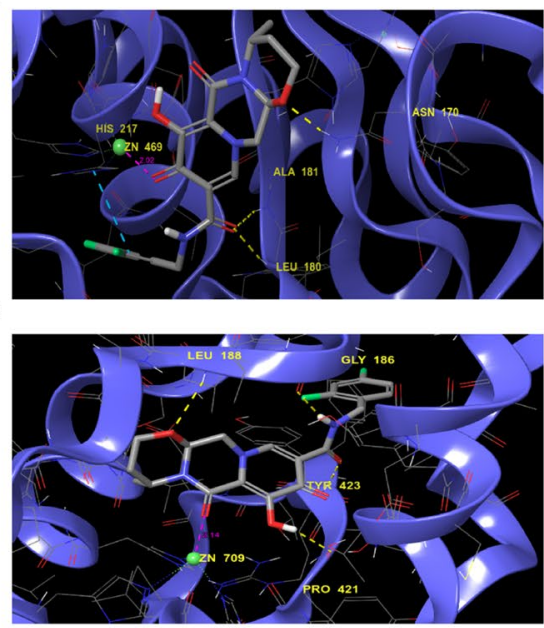

G

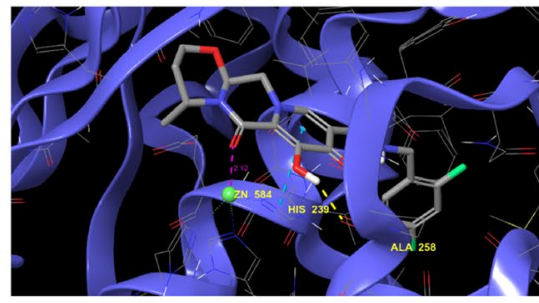

H
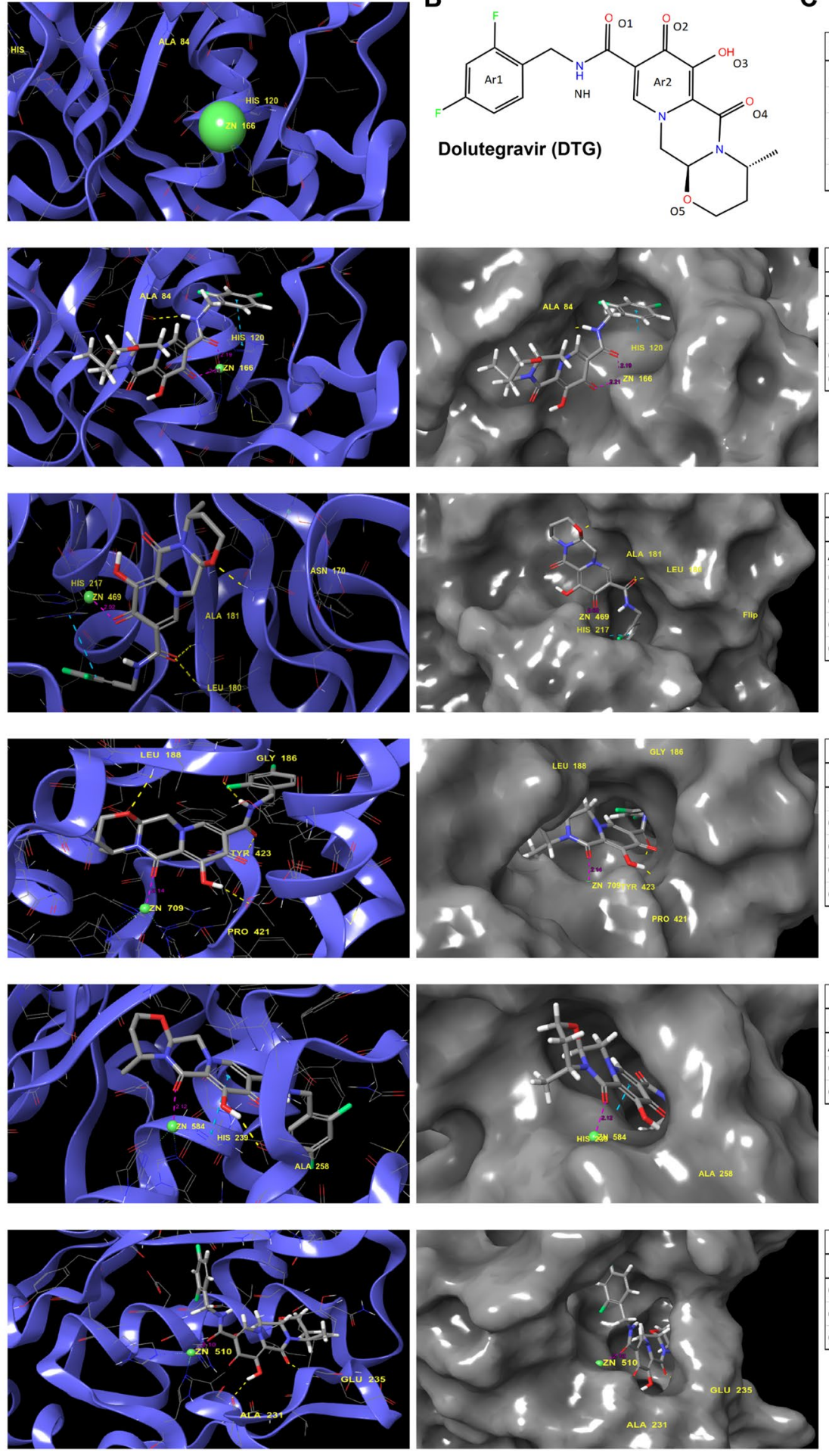

C

\begin{tabular}{|l|c|}
\hline Structure & Energy $\mathbf{( k c a l} / \mathbf{m o l})$ \\
\hline MMP-2 & -6.45 \\
\hline MMP-8 & -8.33 \\
\hline MMP-9 & -9.43 \\
\hline MMP-14 & -9.04 \\
\hline MMP-19 & -7.13 \\
\hline
\end{tabular}

\begin{tabular}{|l|l|l|r|}
\hline \multicolumn{4}{|c|}{ MMP-2 Interactions } \\
\hline Ligand & Receptor & Type & Distance $(\AA)$ \\
\hline Ar1 & His 120 & Pi stacking & 3.59 \\
NH & Ala 84 & Hydrogen bond & 2.28 \\
O1 & Zn 166 & Metal coordination & 2.19 \\
O2 & Zn 166 & Metal coordination & 2.21 \\
\hline
\end{tabular}

\begin{tabular}{|l|l|l|r|}
\hline \multicolumn{3}{|c|}{ MMP-8 Interactions } \\
\hline Ligand & Receptor & Type & Distance (Å) \\
\hline Ar1 & His 217 & Pi stacking & 3.8 \\
O1 & Leu 180 & Hydrogen bond & 1.93 \\
O1 & Ala 181 & Hydrogen bond & 2.32 \\
O2 & Zn 469 & Metal coordination & 2.02 \\
O5 & Asn 170 & Hydrogen bond & 1.91 \\
\hline
\end{tabular}

\begin{tabular}{|c|c|c|c|}
\hline \multicolumn{4}{|c|}{ MMP-9 Interactions } \\
\hline Ligand & Receptor & Type & Distance (Å) \\
\hline $\mathrm{NH}$ & Gly 186 & Hydrogen bond & 1.87 \\
\hline 01 & Tyr 423 & Hydrogen bond & 1.96 \\
\hline 03 & Pro 421 & Hydrogen bond & 2.09 \\
\hline 04 & Zn 709 & Metal coordination & 2.14 \\
\hline O5 & Leu 188 & Hydrogen bond & 2.80 \\
\hline
\end{tabular}

\begin{tabular}{|l|l|l|r|}
\hline \multicolumn{4}{|c|}{ MMP-14 Interactions } \\
\hline Ligand & Receptor & Type & Distance (令) \\
\hline Ar2 & His 239 & Pi stacking & 3.49 \\
O3 & Ala 258 & Hydrogen bond & 1.87 \\
\hline O4 & Zn 584 & Metal coordination & 2.12 \\
\hline
\end{tabular}

\begin{tabular}{|l|l|l|r|}
\hline \multicolumn{4}{|c|}{ MMP-19 Interactions } \\
\hline Ligand & Receptor & Type & Distance (Å) \\
\hline O1 & Zn 510 & Metal coordination & 2.10 \\
O3 & Ala 231 & Hydrogen bond & 2.03 \\
O4 & Glu 235 & Hydrogen bond & 2.14 \\
\hline
\end{tabular}

Fig. 2 Molecular interaction between DTG and MMP. A A 3D representative image of MMP-2 catalytic domain containing $\mathrm{Zn}^{++}$(green ball) is shown. B Chemical structure of DTG with ligand labeling used for molecular docking. C Calculated binding energies for each MMP with DTG using Schrodinger's software suite. D-H 3D representations of molecular docking complex of DTG with D MMP-2, E MMP-8, F MMP-9, G MMP-14, and H MMP-19. 3D representations of molecular docking complexes are shown in ribbon (blue color; left side of the figure) and surface interaction (gray color; middle of the figure) formats. Interactions with $\mathrm{Zn}^{++}$(green ball) and other amino acids (yellow color) are identified. Interactions with $\mathrm{Zn}^{++}$are shown by pink dotted line. Hydrogen bond interaction with amino acids is shown by yellow dotted line. Pi staking is shown by blue dotted line. Interaction details for each complex are provided in the tabular format (right side of the figure) 
Fig. 3B). CAB, also, formed two metal and one salt bridge interactions with $\mathrm{Zn}^{++}$at $\mathrm{Zn} 166 \mathrm{MMP}-2$ and formed two metal and one salt bridge interactions at Zn 584 of MMP-14 (Supplementary Fig. 3C). The distances of all the enzymeligand bonds are shown in the respective enzyme-drug interactions' table (Supplementary Fig. 3A-3C). Docking simulation of BIC and RAL showed the highest binding energy of $-10.97 \mathrm{kcal} / \mathrm{mol}$ for MMP-2 and $-14.53 \mathrm{kcal} / \mathrm{mol}$ for MMP-14, and $-6.29 \mathrm{kcal} / \mathrm{mol}$ for MMP-2 and $-8.66 \mathrm{kcal} /$ mol for MMP-14, respectively (Supplementary Fig. 3A and 3B). Docking simulation of CAB into MMP-2 and 14 showed the highest binding energy -8.58 and $-12.98 \mathrm{kcal} /$ mol, respectively (Supplementary Fig. 3C). These molecular docking assessments confirmed that all INSTIs possess chemical abilities for broad-spectrum MMPs inhibition.

\section{Biodistribution of DTG to Developing Brain During Gestation}

To assess pharmacokinetic (PK) and biodistribution (BD) profiles of DTG during pregnancy, female $\mathrm{C} 3 \mathrm{H} /$ $\mathrm{HeJ}$ mice were administered with $50 \mathrm{mg} / \mathrm{kg}$ DTG daily by oral gavage. DTG was administered throughout the entire gestational period, beginning at the day of vaginal plug detection [gestation day (GD) 0.5] and up to the day of birth of pups (Fig. 3A). DTG levels were measured in maternal plasma during prenatal and postnatal period, up to postnatal day (PND) 21. As DTG is known to transfer to infants through milk in addition to transplacental transfer [40-42], maternal plasma drug levels were measured up to the day of weaning of pups (PND 21). At GD 8.5 and 16.5, high DTG concentrations were detected in plasma of dams, 38,628.63 \pm 4855.53 and 27,296.3 $\pm 2701.15 \mathrm{ng} /$ $\mathrm{mL}$, respectively (Fig. 3B). Since DTG administration was stopped at the day of birth of pups, plasma DTG levels declined over time to $1244.2 \pm 623.20,48.95 \pm 7.39$, and $21.97 \pm 2.42 \mathrm{ng} / \mathrm{mL}$ at PND 4,12 , and 21 , respectively (Fig. 3B). In addition, DTG levels were measured in placenta at GD 16.5 with an average tissue concentration of $3528.04 \pm 316.56 \mathrm{ng} / \mathrm{g}$ (Fig. 3C). The ratio of placental DTG levels to mother's plasma DTG levels at GD 16.5 was 0.12. Daily DTG administration elicited high DTG levels in embryonic brain tissue $(663.6 \pm 75.13 \mathrm{ng} / \mathrm{g})$ at GD 16.5 (Fig. 3D). DTG levels were lower in brain tissue of pups at PND $4(48.1 \pm 2.35 \mathrm{ng} / \mathrm{g}$ at PND 4$)$ compared to those in embryonic brain tissue (Fig. 3D). However, prenatal and postnatal ratios of embryo and pup brain DTG concentrations to mother's plasma DTG levels were similar, 0.024 at GD 16.5 and 0.038 at PND 4. Furthermore, ratio of embryo brain DTG levels to placenta DTG levels at GD 16.5 was 0.18 . In total, PK and BD data confirmed that developing embryo brain is exposed to DTG during pregnancy.

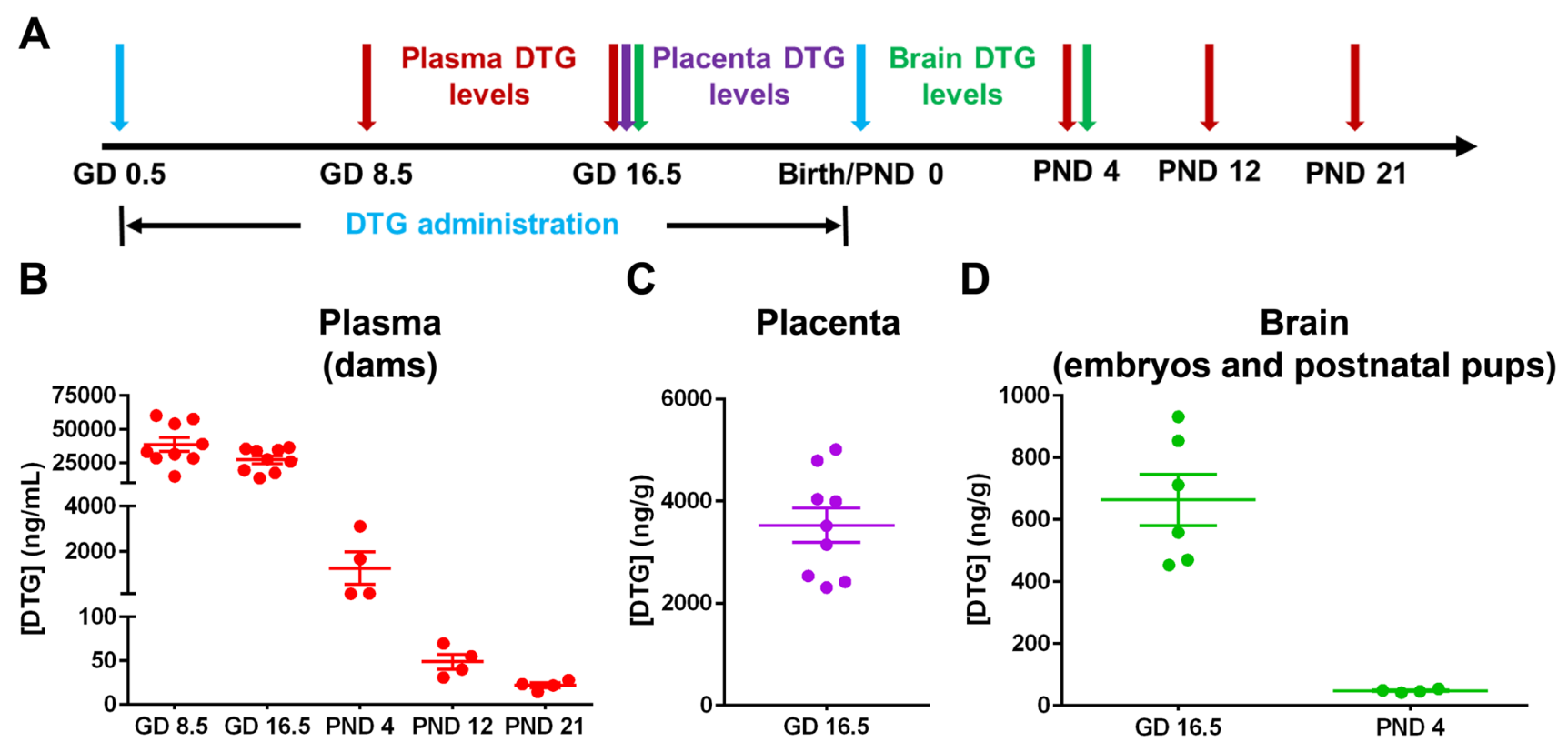

Fig. 3 DTG PK and BD during and after pregnancy. A Schematic presentation of the experimental timeline. B DTG concentrations in plasma of dams. DTG levels were measured during prenatal and postnatal period to evaluate DTG levels in the mother's blood. C DTG concentrations in placental tissue at GD 16.5. D DTG concentrations in brain tissue of embryos or pups. Whole brains from embryos and pups were processed for DTG levels at GD 16.5 and after birth at PND 4. B-D Each sample (plasma or tissue) represents distinct litter. For drug concentration quantitation in all samples, data are expressed as mean $\pm \mathrm{SEM}, N=$ minimum 4 animals at each time point 


\section{DTG Exposure During Gestation Infrequently Leads to Neural Tube Defects}

To determine the effect of DTG during pregnancy on embryo development, female $\mathrm{C} 3 \mathrm{H} / \mathrm{HeJ}$ mice were administered DTG $(50 \mathrm{mg} / \mathrm{kg}$ ) or vehicle (control) orally every day. Daily DTG administration at a $50 \mathrm{mg} / \mathrm{kg}$ dose provided plasma drug levels in pregnant dams of $10 \times$ the maximal DTG concentration $\left(C_{\max }\right)$ achieved in human plasma at therapeutic doses (Fig. 3B) [43-46]. Pregnant dams were randomly assigned to DTG or vehicle group. DTG or vehicle was administered by oral gavage from GD 0.5 to GD 15.5 (Fig. 4A). Periconceptional usage of DTG by women had more adverse pregnancy outcomes compared to drug initiation during pregnancy $[9,10,47]$. Thus, DTG administration was started at the day of vaginal plug detection (GD 0.5). This approach maintained parallel drug exposures among all pregnant dams. No differences were observed in maternal body weight gain during gestation between DTG and control groups (Fig. 4B). At GD 16.5, embryos were harvested and evaluated for neural tube defects (NTDs). Embryo phenotypes in DTG or vehicle treatment groups are summarized in Fig. 4C. The litter size and viability and resorption rates were similar between groups. The mean litter size in control group was 7.1 and in DTG group was 7.6. The total resorption (\%) in control dams was $18.75 \%$ ( $n=9$ litters, 12 out of 64 total implants), and in DTG-treated dams was $20.76 \%(n=17$ litters, 27 out of 130 total implants). In vehicle-treated control group, out of 52 viable embryos, no NTDs were detected (0\%) (Fig. 4B, D), whereas in DTG-treated group, 1 out of 103 viable embryos showed NTDs, giving an incidence rate of $0.9 \%$ (Fig. 4C, D). The one embryo with NTD exhibited exencephaly (Fig. 4D). From total viable embryos, $99.02 \%$ (102 out of 103 viable embryos) had no abnormalities following DTG $(50 \mathrm{mg} / \mathrm{kg} /$ day $)$ treatment. Taken together, in utero DTG exposures showed limited NTDs in fetuses.

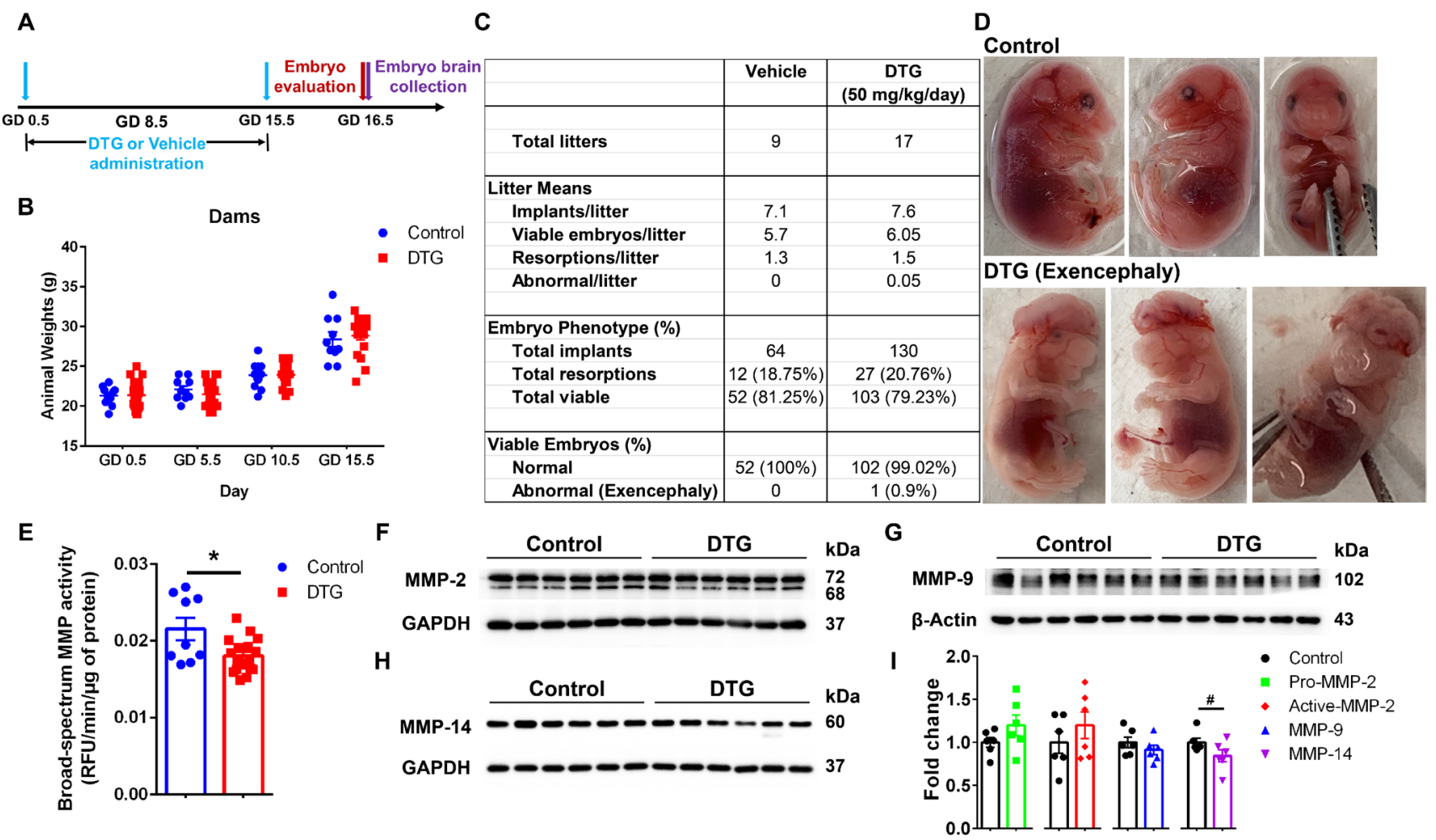

Fig. 4 In utero DTG exposure effects on MMP activity in the fetal CNS. A Schematic presentation of timeline of the experiment. B Weights of dams from GD 0.5 to GD 15.5. No differences between DTG and control groups were observed. C Embryo phenotype assessment. D Representative images of embryos after vehicle (control) or DTG treatment at GD 16.5. From DTG group, one embryo out of 103 viable embryos showed exencephaly. E Fluorometric substrate assay. Broad-spectrum MMP activity in a whole brain tissue homogenate of embryos at GD 16.5 was evaluated. Data are expressed as the mean \pm SEM, $N=9$ animals (control) and $N=17$ animals (DTG). $t$ test (two-tailed) with Welch's correction was used to compare the broad-spectrum MMP activity between DTG and control groups $\left({ }^{*} p<0.05\right)$. F Protein levels of MMP-2 in embryo brain tissue. G Protein levels of MMP-9 embryo brain tissue. H Protein levels of MMP-14 embryo brain tissue. F, G Each lane is representative of six animals from each group. I Quantitation of protein levels in DTG compared to control using ImageJ software. Data are expressed as the mean \pm SEM, $N=6$ animals/group. $t$ test (two-tailed) with Welch's correction was used to compare protein levels of individual MMP between DTG and control $\left({ }^{\#} p<0.1\right)$ 


\section{In UteroDTG Exposure Inhibits Fetal Brain MMP Activity}

To determine the effects of in utero DTG exposure on MMP activity in the developing embryo brain, randomly selected pregnant dams $(\mathrm{C} 3 \mathrm{H} / \mathrm{HeJ}$ mice) were administered DTG $(50 \mathrm{mg} / \mathrm{kg}$ ) or vehicle (control) orally each day by oral gavage from GD 0.5 to 15.5 . In order to maintain periconceptional DTG usage $[9,10,47]$ and equal drug exposures among dams, DTG administration was started at the day of vaginal plug detection (GD 0.5). Whole brain tissues were isolated from normal viable embryos (GD 16.5) from both groups (DTG and control) and were further processed to determine effects of DTG on MMP activity in the developing CNS. Herein, broad-spectrum MMP activity was determined from total protein isolate of brain tissue using fluorometric substrate. As DTG is a broad-spectrum MMPs inhibitor, and there are complexities in MMPs expressions, overlapping functions, and co-dependent activations/functions [20, $22,24,39]$, broad-spectrum activity was determined to reflect MMPs activities [48]. Broad-spectrum MMP activity was significantly inhibited by DTG in the embryonic brain compared to controls (Fig. 4E). Later, protein expression levels of known MMPs involved in embryonic brain development were determined. These were MMP-2, 9, and 14 (Fig. 4F-H). No significant differences were observed between DTG and controls for protein levels of any of these MMPs (Fig. 4I).

\section{In Utero DTG Exposure Impairs Postnatal Neurodevelopment}

To assess the effects of in utero DTG exposure on postnatal neurodevelopment, adolescent mice pups were evaluated at PND 28 (Fig. 5A). Mice pups at this stage of development (PND 28) are equivalent to humans of 2 years of age [49]. Female $\mathrm{C} 3 \mathrm{H} / \mathrm{HeJ}$ mice were treated orally every day with DTG $(50 \mathrm{mg} / \mathrm{kg})$ or vehicle (control) through the entire period of gestation starting at GD 0.5 (Fig. 5A). Pregnant dams were randomly assigned to DTG or vehicle group. Average littler size was similar between DTG (3.5) and control (4.7) groups (Fig. 5B). In addition, male to female ratios per litter were similar for control (2.1) and DTG (2.0) (Fig. 5B). There were no structural malformations or variations in newborn pups in either treatment group. During the preweaning growth period, the survival rate of pups was comparable between DTG and control groups. Survival rate of pups between PND 0 and 4 was $90.4 \%$ for controls and $92.8 \%$ for DTG. Survival rate of pups was $100 \%$ between PND 4 and 21 in both groups. Further body weights of pups were measured during preweaning duration. Animal weights from DTG-treated group were significantly lower compared to control at PND 12 and 21 (Fig. 5C). Average body weights of control and DTG pups were $7.2 \pm 0.2$ and $9.2 \pm 0.2 \mathrm{~g}$ (control) and $5.1 \pm 0.4$ and $7.5 \pm 0.4 \mathrm{~g}$ (DTG) at PND 12 and 21, respectively. Furthermore, between age PND 28 and 34, live animals were evaluated for biochemical changes in the brain by magnetic resonance imaging (MRI) (Fig. 5D-F). All the tests were performed around 6 days post weaning to avoid confounding effect of stress related to separation from mother [50,51]. Microstructural and metabolite measurements were conducted in live pups using bioimaging methods, diffusion tensor imaging (DTI), and magnetic resonance spectroscopy $\left({ }^{1} \mathrm{H}\right.$ MRS), respectively [30] (Fig. 5D-F). First, pups were scanned using DTI to determine microstructural changes in six different brain regions, hippocampus (HI), cortex (CT), striatum (ST), thalamus (TH), hypothalamus (HY), and cerebellum (CE). Color-coded diffusion directions in brain of DTG group pups are shown in Fig. 5D. In all six brain regions, fractional anisotropy (FA) values were significantly lower in the DTG group compared to those in the control group (Fig. 5E). As FA represents anisotropic movement of water molecules along the axons, reduction in FA values indicated axonal and/or myelin damage $[30,52]$ in developing brain of adolescent pups in the DTG-treated group. In addition, the analysis of FA values assessed the effect of in utero DTG exposures on male and female pups. This allowed evaluation of sex as a biological variant (Supplementary Fig. 4). In male pups, FA values were significantly reduced in HI, CT, $\mathrm{ST}$, and HY, and trend of reduced FA values was observed in $\mathrm{TH}$ and CE. In female pups, significant reduction was noted only in TH and trend of decrease in HI (Supplementary Fig. 4). Further, the same pups were scanned using ${ }^{1} \mathrm{H}$ MRS to measure $\mathrm{N}$-acetylaspartate (NAA), total choline (tCho), and total creatine (tCre) in hippocampus (HI) only (Fig. 5F). NAA is a highly concentrated metabolite in the CNS and is a neuron-specific metabolite that acts as a non-invasive ${ }^{1} \mathrm{H}$ MRS marker for neuronal integrity, health, and cell number $[30,53]$. NAA levels in $\mathrm{HI}$ were significantly reduced in the DTG group compared to those in the control group (Fig. 5F), indicating neuronal and/or synaptic damage. In addition, significant increase in tCho levels in DTG group identified the neuroinflammation [54]. No differences were observed in the internal reference tCre [55]. Similar to DTI, sex differences were evaluated in the ${ }^{1} \mathrm{H}$ MRS study (Supplementary Fig. 5). NAA was significantly reduced in females of DTG group compared that of control group. No significant differences between groups were observed for other metabolite concentrations in either of the sex (Supplementary Fig. 5). Together, both in vivo MRI assessments, DTI and ${ }^{1} \mathrm{H}$ MRS, identified neuronal damage and neuroinflammation in pups who were exposed to DTG in utero.

For biological validation, transcriptomic evaluation of total RNA was performed on isolated $\mathrm{HI}$ tissue from pups following MRI assessments (Fig. 5G-K). Isolated total RNAs 


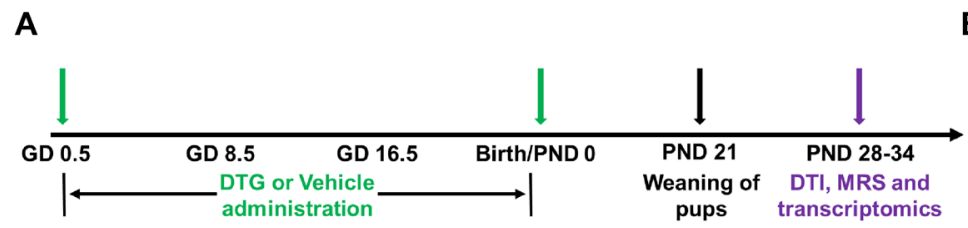

\begin{tabular}{|l|c|c|}
\hline & Control & DTG \\
\hline Total dams evaluated & 4 & 4 \\
\hline No. of pups delievered per litter & 4.7 & 3.5 \\
\hline No. of male pups delievered per litter & 3.2 & 2.2 \\
\hline No. of female pups delievered per litter & 1.5 & 1.2 \\
\hline \% pup survival (birth to PND 4) & 90.4 & 92.8 \\
\hline$\%$ pup survival (PND 4 to PND 21) & 100 & 100 \\
\hline
\end{tabular}

C
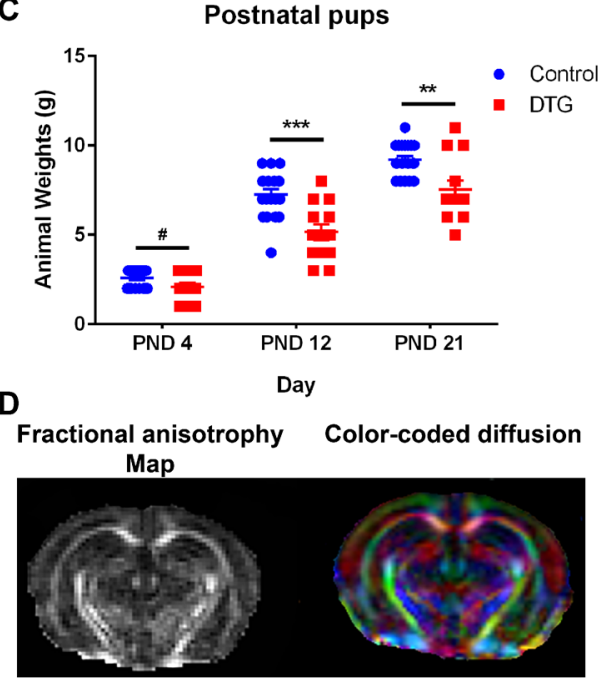

Red: Left-Right; Green: Up-Down; Blue: In-Out

$E$

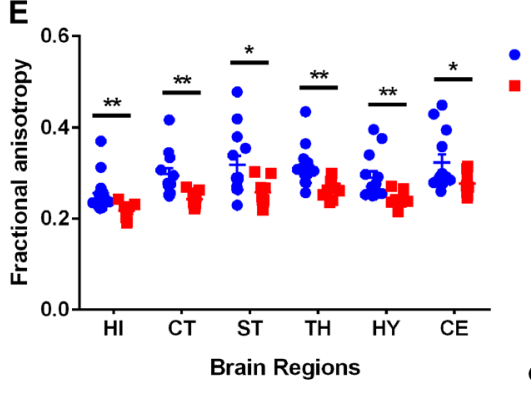

$\mathbf{F}$

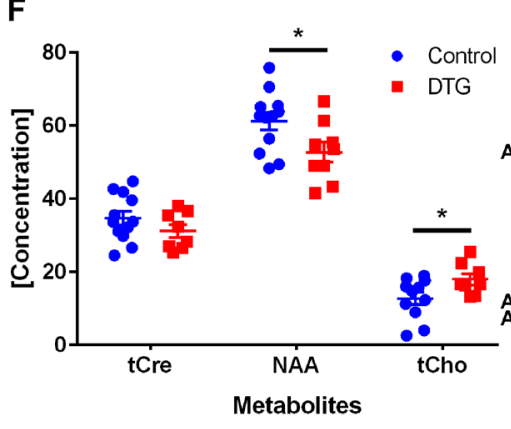

G
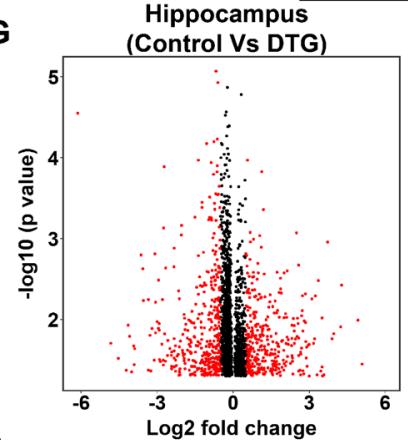

I

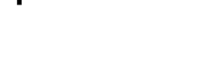

Synaptic Granulocyte Adhesion and Potentiation Neuroinflammation Signaling Pathway FGF Signaling Regulation of the Epithelial-Mesenchymal Transition Pathway icos-iCOSL Signaling in T Helper Cells Synaptogenesis Signaling Pathway Antigen Presentation Pathway Th1 and Th2 Activation Pathway Agranulocyte Adhesion and Diapedesis Heparan Sulfate Biosynthesis Heparan Sulfate Biosynthesis (Late Stages) Dermatan Sulfate Biosynthesis
Chondroitin Sulfate Biosynthesis Human Embryonic Stem Cell Pluripotency Iron homeostasis signaling pathway Calcium Signaling Chondroitin Sulfate Biosynthesis (Late Stages) Dermatan Sulfate Biosynthesis (Late Stages) Dendritic Cell Maturation CREB Signaling in Neurons

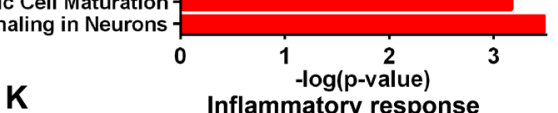

J Neuronal processes

K Inflammatory response

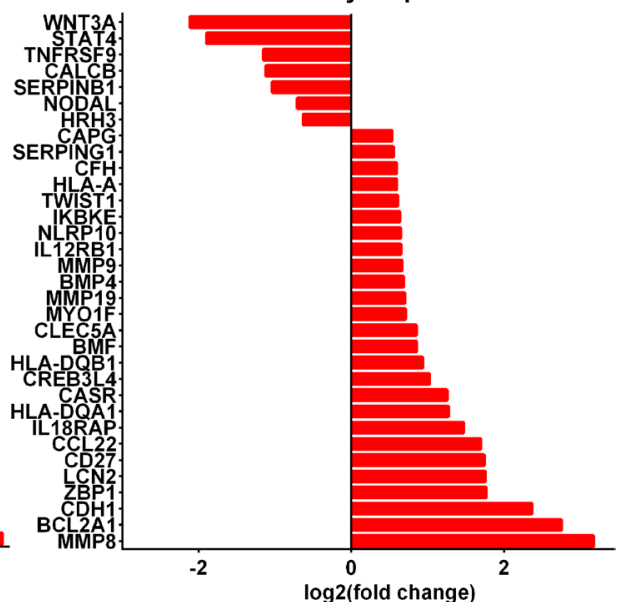

from HI region of brain of 4 randomly selected pups from 4 different dams for each group were used. Comparison of genes between DTG-treated group and vehicle-treated group (control) showed a total of 2594 genes significantly differentially expressed (Fig. 5G, H), out of which 1716 genes were downregulated and 878 were upregulated. Transcriptomic analysis revealed that majority of differentially expressed genes were associated with pathological processes/pathways including aberrant biosynthesis of extracellular matrix components, neuroinflammation, axonal guidance and synaptogenesis, and infiltration of immunocytes in $\mathrm{HI}$ of pups from DTG group compared to controls (Fig. 5I-K). 
४Fig. 5 Postnatal neurodevelopment following in utero DTG exposure. A Schematic presentation of timeline. B Pregnancy and postnatal outcomes. C Postnatal animal (pups) weights. D Representative diffusion tensor imaging (DTI) image of PND 28 pup from DTG group. Red: left-right; green: up-down; blue: in-out. E DTI: fractional anisotropy (FA) measurements in six different brain regions: hippocampus (HI), cortex (CT), striatum (ST), thalamus (TH), hypothalamus (HY), and cerebellum (CE). F Magnetic resonance spectroscopy ( ${ }^{1} \mathrm{H}$ MRS): metabolite concentration measurements in hippocampus. Total creatine (tCre), $N$-acetylaspartate (NAA), and total choline (tCho) were measured. C, E, F Data are expressed as mean \pm SEM, $N=$ minimum 8 animals/group for each parameter evaluation. Student's $t$ test (two-tailed) was used to compare animal weights at each time point, FA (DTI) in each brain region or each metabolite concentration $\left({ }^{1} \mathrm{H}\right.$ MRS), between DTG and control $\left({ }^{\#} p<0.1,{ }^{*} p<0.05, * * p<0.01\right.$, $* * * p<0.001)$. G-K Comparative transcriptomic analysis of total RNA from hippocampus region between DTG and control groups. $N=4$ animals/group. G Volcano plot; $p \leq 0.05$; red color: log2FoldChange $\geq 0.5$ or $\leq-0.5$. H Total number of upregulated and downregulated genes. I Major affected pathways were determined by using Ingenuity pathway analysis (IPA). J, K Differentially expressed genes associated with neuronal processes and neuroinflammation

Major affected genes which showed aberrant biosynthesis of extracellular matrix components were NDST3, NDST4, HS3ST2, and HS6ST3 (Fig. 5I-K). In addition, differentially expressed genes served to confirm putative mechanisms for neuronal damage, inflammation, and immune cell infiltration (Fig. 5I-K). Genes associated with these mechanisms are categorized by differential expression. Those with increased expression were identified as MMP-8, MMP-9, MMP-19, CDH1, CREB3L4, CREB3L3, EFNA4, BMP4, Npas4, ADAMTS18, ADAMTS14, BCL2A1, ZBP1, LCN2, CD27, CCL22, IL18RAP, HLA-DQA1, CASR, IL12RB1, NLRP10, HLA-DQB1, BMF, CLEC5A, MYO1F, IKBKE, TWIST1, HLA-A, CFH, SERPING1, and CAPG (Fig. 5J, K). Those with decreased expression were ITPR1, TYRO3, CDH18, ADCY8, HS6ST3, GRIN3A, WNT2, CHRNA4, ADAMTS16, CDH22, KCNJ12, HTR1B, BMP3, Baiap211, NDST3, GABRA3, HS3ST2, CPLX3, NDST4, CHRNA5, WNT3A, NTS, HRH3, NODAL, SERPINB1, CALCB, TNFRSF9, and STAT4 (Fig. 5J, K). Moreover, top network identified TNF- $\alpha$ as a master regulator with 17 focus molecules, indicating the inflammatory response (Supplementary Fig. 6). According to the drug ratio relationship between dam's plasma and embryo brain (Fig. 3), DTG level in pup's brain is predicted to be below detection limit $(0.1 \mathrm{ng} / \mathrm{g})$ at PND 28 after cessation of DTG administration to dam at the day of birth of pups. Thus, inhibition of MMP activity due to direct drug interaction is not expected at PND 28 or thereafter in the current study design (Fig. 5A). In all, the observed postnatal neuropathology can be linked to DTG's effect on the developing embryo CNS.

\section{Discussion}

With the widespread global use of DTG-based regimens and noted ADE in clinical and preclinical studies, defining in utero effects of drug on fetal development is timely. This includes the mechanism(s) of action on the developing CNS [2, 9-13]. Prior works focused on determining relationships between folate levels or transport pathways and DTG-associated birth defects failed to conclusively generate any cause and effect relationships [11, 56-59]. Exploring alternative mechanisms was required [11, 56-59]. Herein, for the first time, we show that DTG inhibits MMPs activities in fetal brain during gestation and as such impairs neurodevelopment. DTG was found to be a broad-spectrum inhibitor of MMPs. The drug was found to bind $\mathrm{Zn}^{++}$at the catalytic domain, leading to inhibition of MMPs activities. Moreover, studies in pregnant mice showed that DTG can cross the placental barrier, accumulate in the fetal CNS, and inhibit MMP activity during the critical period of brain development. Further postnatal evaluation of brain health following in utero DTG exposure showed neuronal impairment associated with neuroinflammation.

The role of MMPs in neural development is of critical importance as dysregulation of MMP activity is a hallmark of neurodevelopmental disorders [15-26]. MMPs regulate multiple processes of neurodevelopment. These include, but are not limited to, angiogenesis, neurovasculature remodeling, establishment and integrity of blood-brain barrier (BBB), neurogenesis, neuronal migration, myelination, axonal guidance, synaptogenesis, synaptic plasticity, and tissue remodeling [15-26]. Several members of MMP family have been implicated in such processes. Notably, four MMPs, MMP-2, 8, 9, and 14, have been studied extensively for their roles in angiogenesis and neurogenesis [15-26]. Our data showed that DTG is a broad-spectrum MMP inhibitor with strong inhibitory effect (lowest $\mathrm{IC}_{50}$ values among tested MMPs), particularly on MMP-2, 8, 9, and 14. In addition, clinical trials have revealed that prolonged treatment with broad-spectrum MMP inhibitors has severe adverse effects on physiological processes [39]. Thus, being a broad-spectrum inhibitor of MMPs and being able to reach to embryonic CNS during critical period of development, DTG imposes a noted risk for neurodevelopment.

In addition to lower body weights, neuronal damage and neuroinflammation was observed in adolescence mouse pups (PND 28-34) of DTG-treated group during postnatal growth assessments. It is noteworthy that DTG administration to mother was stopped at birth of pups and DTG concentrations in brain tissue were very low or undetectable level at PND 28. These data suggest that the aberrations resulted from inhibition of MMPs activities during gestation were not recovered or extended to observed pathology up to PND 28. 
Interestingly, increased RNA levels of MMP-8, MMP-9, and MMP-19 were observed in $\mathrm{HI}$ at postnatal transcriptomic evaluation. DTI, ${ }^{1} \mathrm{H}$ MRS, and transcriptomic data validated neuronal injury, neuroinflammation, and immunocyte infiltration into the brain, which could explain increase in these MMPs [60]. In our prior studies, we examined metabolomic profiles in adult rodent brain tissues that were affected by DTG. These works included analyses of energy and oxidative stress pathways [61]. Interestingly, the oxidative stress pathways induced by DTG were significantly attenuated when this antiretroviral drug was administered as an intramuscular extended-release poloxamer-coated aqueous nanoformulation. These therapeutic benefits of nanoformulations were attributed to slow release of the parent drug from the depot over an extended period of time and neuroprotective properties of poloxamers. Thus, such neuroprotective activities seen by formulation design demonstrate the potential of extended-release nanoformulations to attenuate DTG-associated neurotoxicity that includes the findings described in this report.

The chemical property of DTG to chelate divalent cations enables it to interact with $\mathrm{Zn}^{++}$in the catalytic domain of MMPs. This results in the inhibition of MMPs activities. All INSTIs including CAB, BIC, RAL, and elvitegravir (EVG) possess MBP to interact with metal ions. Our preliminary molecular docking evaluation showed that $\mathrm{CAB}$, $\mathrm{BIC}$, and RAL can interact with $\mathrm{Zn}^{++}$at the catalytic domain of MMP-2 and MMP-14, indicating that not only DTG but the entire INSTI drug class could affect MMPs activities. Further research efforts are required to evaluate the effects of other INSTIs on MMPs and on CNS development following in utero exposure. With long-acting CABENUVA (CAB co-administered with rilpivirine) approved recently (January 2021) by the US FDA as a monthly injectable [62], and with positive data of once in two months CAB-regimen longacting injectable from phase III clinical trial (ATLAS-2 M study) [63], effects of sustained levels of CAB on MMPs remain to be determined.

Identifying the roles of the MMPs and their broadspectrum inhibition in physiological processes is complex. Indeed, clinical trials with broad-spectrum MMP inhibitors revealed that prolonged treatment causes ADE. This reflected in cessation of human clinical trials for more than fifty broad-spectrum MMP inhibitors [39]. As DTG is a zincbinding inhibitor, observed undesired adverse effects on the developing CNS were mostly due to broad-spectrum MMP inhibition. However, potential cross-inhibition of a disintegrin and metalloproteinase (ADAM) family members and of a disintegrin and metalloproteinase with thrombospondin motifs (ADAMTS) family members by DTG, in addition to inhibition of MMP activity, could be yet another potential mechanism [39, 64, 65]. Such cross-inhibition of ADAM or ADAMTS members by zinc-binding broad-spectrum MMP inhibitors is known due to structural similarities between MMPs and ADAM/ADAMTS at catalytic domains. DTG is a potent INSTI with $\mathrm{IC}_{50}$ value of $2.7 \mathrm{nM}$ [66]. However, the recorded $\mathrm{IC}_{50}$ values for DTG inhibition of MMP activities were high. These values were ranged between 10 and $300 \mu \mathrm{M}$. Moreover, calculated $\mathrm{IC}_{50}$ values for DTG, in the current study, are higher than clinically relevant concentrations after considerations for required plasma-protein binding adjustments [59]. Long-term, daily administration of DTG in HIV-1-infected persons, transfer easily across the placental barrier, and exposure of a developing CNS to drug during the entire gestational period and through breast feeding require further evaluation. Certainly, observed DTGassociated MMP inhibition was statistically significant; however, inhibition can be realized at modest extent. It is well known that balanced regulation of MMPs activities is essential for normal biological functioning and growth [19, $20,39]$. Dysregulation of activity of any single or multiple MMPs in either direction, increase or decrease, leads to adverse effects. Fetal neurodevelopmental processes during gestation are highly susceptible to any chemical challenges. Thus, DTG readily existing at embryo CNS throughout the gestational period and reduced MMPs activities at notable extent can potentially cause damage and lead to developmental disorders. It, also, needs to be noted that evaluation of MMP activity in embryo CNS was completed only at GD 16.5. Other gestational time points and intensity of the drug impact at those time points remain unknown. However, observed postnatal brain aberrations in adolescent mice pups affirmed DTG-associated fetal brain toxicity as consequence of in utero exposures. Also, it needs to be emphasized that the current study was designed for proofof-concept only. The intent was to determine any or all effect of in utero DTG exposure on MMP activity in embryo brain and whether or not it could affect prenatal and or postnatal neurodevelopment. Thus, for this initial assessment, a higher dosage $(50 \mathrm{mg} / \mathrm{kg} /$ day of mice weight $)$ was selected that could achieve $10 \times$ the maximal DTG concentration $(C \max )$ recorded in human plasma. Recently, increased rates of fetal defects in mice embryos exposed to therapeutic DTG doses during pregnancy compared to supratherapeutic levels were reported [11]. The results of these findings supported a causal relationship of DTG at therapeutic doses with increased risk for fetal defects. This included neural tube defects (NTDs). Assessments of the findings recorded at a clinical therapeutic dosage will be the focus of our own future works.

The percentage of NTDs following in utero DTG exposure was low and seen only in 1 out of 103 embryos $(0.9 \%)$. Although the number of litters evaluated were few (17 total) in the current study, the observation is similar to overall clinical prevalence of NTDs among infants born to women receiving DTG at conception $(\sim 0.3 \%)$ [10, 
67]. In addition to adverse pregnancy outcomes, DTG is associated with neuropsychiatric adverse events (NPAEs) in adults $[68,69]$ and clinically significant weight gain, especially in females [70-73]. Notably, NPAEs are usually reversible upon discontinuation of DTG. Inhibition of certain MMP's activity, related compensatory increase in other MMP activity and/or expression and affected MMP-dependent upstream or downstream biological and immunological processes, could be an underlying mechanism for these known DTG-associated adverse effects [23, 39, 74-78]. Recently, vascular defects (cranial and spinal and hemorrhagic bleeds) were reported at 2- to threefold higher rate in mice embryos exposed to DTG in utero. In these studies, vascular defects were observed at therapeutic levels of DTG [11], supporting the notion that DTG could affect vascular integrity during embryo development [11]. Angiogenesis and vascular remodeling are dependent, in part, on MMP activity [79, 80]. Synthetic MMPs inhibitors and endogenous tissue inhibitors of metalloproteinases (TIMPs) possess antiangiogenic properties [79, 80]. Moreover, MMP knockout mice show angiogenesis defects and impaired vascular remodeling $[19,20]$. Thus, DTG inhibition of MMPs activities could, in measure, explain such vascular defects observed in the mouse embryo [11]. Potential dose-escalation DTG effects on vascular development and MMPs activities require future investigation.

In coming years, significant numbers of fetuses will be exposed to DTG. Due to a breakthrough pricing agreement made in September 2017 to accelerate the availability of generic DTG-based regimens in RLCs at the cost of $\$ 75$ US dollars/person/year, around 100 RLCs have implemented transitioning to DTG-based regimen in national treatment guidelines by mid-2020 [81]. In 2019, 6.9 million people had access to generic DTG regimen and up to 15 million people worldwide would be treated with DTG by the year 2025 [7, 8, 81, 82]. This includes women of child-bearing age who remain a significant infected population (UNAIDS data, 2020) [83]. It is estimated that there are 15.5 million women, 15-49 years old, living with HIV worldwide [84]. Moreover, women accounted for about $48 \%$ of all new HIV-1 infections in 2019 [83]. Thus, with increased availability of DTG-based regimens and its inclusion in recommended national treatment guidelines globally, significant population of women of child-bearing age will be treated with DTGbased regimens.

Although the current proof-of-concept study provides a novel mechanism cross-validated with multidisciplinary research approach, a few limitations are recognized. First, dose-dependent cause and effect assessment was not performed. The study was conducted at one dosage $(50 \mathrm{mg} /$ $\mathrm{kg}$ ), which achieved supratherapeutic plasma DTG levels in pregnant dams. Second, embryos were evaluated only at one time point of gestation (GD 16.5). Third, the study was focused on brain development; however, the effects on different developmental processes that are dependent on MMP activity such as neurogenesis and angiogenesis were not evaluated. Fourth, the study did not include assessment of functional and structural anomalies in other developmental organs such as placental, cardiac, or skeletal defects. Comprehensive evaluations consisting effect of dose-dependent DTG inhibition of MMPs activities on neurodevelopment that would include neurogenesis and angiogenesis during different stages of gestation will be completed in future studies. This includes any links to long-term postnatal neurologic outcomes.

The mechanisms that affect human neurodevelopment following in utero exposure of DTG are not known. An observational clinical study reported increased risks of neurodevelopmental aberrations by in utero DTG exposure in HIV-exposed but uninfected (CHEU) children [2]. In full consideration of prior human studies, it is timely to elucidate any potential links to adverse events, no matter how infrequent, in order to provide the most effective care to women and their fetuses at risk or infected by HIV-1. Continued monitoring of children during development will determine accurate DTG-linked neurodevelopmental effects with MMP activities. These studies would be completed during pregnancy and postnatal development. Further understanding for drug formulation and delivery would serve to maximize the drug's benefits and minimize any untoward effects. In this report, we demonstrate that DTG inhibition of MMPs activities during gestation can affect pre- and postnatal neurodevelopment in mice. The study provides a new potential mechanism that can serve to advance translational research in evaluating the effects of in utero exposure to DTG and potentially to other new HIV-1 integrase inhibitors on neurodevelopment.

Supplementary Information The online version contains supplementary material available at https://doi.org/10.1007/s12035-021-02508-5.

Acknowledgements Authors thank Bhagya Laxmi Dyavar Shetty for technical assistance with drug quantitation by UPLC-MS/MS; Melissa Mellon and Lirong Xu for technical assistance with mouse MRI imaging; and Saumi Mathews for technical assistance with IPA analysis. The authors also thank the technical support from UNMC Core Facilities that include genomics core, bioinformatics and systems biology core, computational chemistry core, and bioimaging core (MRI).

Author Contribution A.N.B.: conceived project, devised central hypothesis and the project's scientific approach, designed and performed all the experiments, collected, analyzed, and interpreted data sets, prepared figures, wrote the original draft of manuscript, edited and reviewed the manuscript; J.M.M.: provided technical guidance and analyzed the UPLC-MS/MS data; Y.L. supervised and analyzed MRI data; B.J.E.: provided technical guidance for the project; H.E.G.: provided overall project guidance, research infrastructure, funding, writing, and review of the manuscript. All authors critically evaluated and approved the final manuscript prior to submission. 
Funding This research is supported in part by the National Institutes of Health grants P01 DA028555, P01 DA028555-09S, R01 NS36126, P30 MH062261, R01 MH121402, R01 MH115860, and 2R01 NS034239 to H.E.G; R01 AI158160 and R01AI145542 to B.E. and H.E.G.; and a Bioimaging Core (MRI) grant from the Nebraska Center for Nanomedicine to A.N.B.

Data Availability The datasets used during the current study are available from the corresponding author on reasonable request.

Code Availability Not applicable.

\section{Declarations}

Ethics Approval All animal studies were approved by the University of Nebraska Medical Center Institutional Animal Care and Use Committee (IACUC) in accordance with the standards incorporated in the Guide for the Care and Use of Laboratory Animals (National Research Council of the National Academies, 2011).

Consent to Participate Not applicable.

\section{Consent for Publication Not applicable.}

Competing Interests Drs. Benson Edagwa and Howard E. Gendelman are co-founders of Exavir Therapeutics, Inc., a biotechnology company focused on the development of long-acting antiretroviral medicines. The remaining authors declare that they have no competing interests.

Open Access This article is licensed under a Creative Commons Attribution 4.0 International License, which permits use, sharing, adaptation, distribution and reproduction in any medium or format, as long as you give appropriate credit to the original author(s) and the source, provide a link to the Creative Commons licence, and indicate if changes were made. The images or other third party material in this article are included in the article's Creative Commons licence, unless indicated otherwise in a credit line to the material. If material is not included in the article's Creative Commons licence and your intended use is not permitted by statutory regulation or exceeds the permitted use, you will need to obtain permission directly from the copyright holder. To view a copy of this licence, visit http://creativecommons.org/licenses/by/4.0/.

\section{References}

1. World Health Organization (2016) Consolidated guidelines on the use of antiretroviral drugs for treating and preventing HIV infection: recommendations for a public health approach-second edition. https://www.who.int/hiv/pub/arv/chapter4.pdf?ua=1. Accessed February 272021

2. Crowell CS, Williams PL, Yildirim C, Van Dyke RB, Smith R, Chadwick EG, Seage GR 3rd, Diperna A, Hazra R, Pediatric HIVACS (2020) Safety of in-utero antiretroviral exposure: neurologic outcomes in children who are HIV-exposed but uninfected. AIDS 34(9):1377-1387. https://doi.org/10.1097/QAD.00000 00000002550

3. Ramokolo V, Goga AE, Slogrove AL, Powis KM (2019) Unmasking the vulnerabilities of uninfected children exposed to HIV. BMJ 366:14479. https://doi.org/10.1136/bmj.14479

4. Evans C, Jones CE, Prendergast AJ (2016) HIV-exposed, uninfected infants: new global challenges in the era of paediatric HIV elimination. Lancet Infect Dis 16(6):e92-e107. https://doi.org/10. 1016/S1473-3099(16)00055-4
5. Department of Health and Human Services (DHHS), Panel on Antiretroviral Guidelines for Adults and Adolescents. Guidelines for the use of antiretroviral agents in adults and adolescents living with HIV. https://clinicalinfo.hiv.gov/sites/default/files/guidelines/ documents/AdultandAdolescentGL.pdf. Accessed June 112021

6. Brenner BG, Wainberg MA (2017) Clinical benefit of dolutegravir in HIV-1 management related to the high genetic barrier to drug resistance. Virus Res 239:1-9. https://doi.org/10.1016/j.virusres. 2016.07.006

7. Dorward J, Lessells R, Drain PK, Naidoo K, de Oliveira T, Pillay Y, Abdool Karim SS, Garrett N (2018) Dolutegravir for first-line antiretroviral therapy in low-income and middle-income countries: uncertainties and opportunities for implementation and research. Lancet HIV. https://doi.org/10.1016/S2352-3018(18) 30093-6

8. Hill A, Clayden P, Thorne C, Christie R, Zash R (2018) Safety and pharmacokinetics of dolutegravir in HIV-positive pregnant women: a systematic review. J Virus Erad 4(2):66-71

9. Zash R, Makhema J, Shapiro RL (2018) Neural-tube defects with dolutegravir treatment from the time of conception. N Engl J Med 379(10):979-981. https://doi.org/10.1056/NEJMc1807653

10. Zash R, Holmes L, Diseko M, Jacobson DL, Brummel S, Mayondi G, Isaacson A, Davey S, Mabuta J, Mmalane M, Gaolathe T, Essex M, Lockman S, Makhema J, Shapiro RL (2019) Neural-tube defects and antiretroviral treatment regimens in Botswana. N Engl J Med 381(9):827-840. https://doi.org/10.1056/NEJMoa1905230

11. Mohan H, Lenis MG, Laurette EY, Tejada O, Sanghvi T, Leung KY, Cahill LS, Sled JG, Delgado-Olguin P, Greene NDE, Copp AJ, Serghides L (2020) Dolutegravir in pregnant mice is associated with increased rates of fetal defects at therapeutic but not at supratherapeutic levels. EBioMedicine 63:103167. https://doi. org/10.1016/j.ebiom.2020.103167

12. Schnoll JG, Temsamrit B, Zhang D, Song H, Ming GL, Christian KM (2019) Evaluating neurodevelopmental consequences of perinatal exposure to antiretroviral drugs: current challenges and new approaches. J Neuroimmune Pharmacol. https://doi. org/10.1007/s11481-019-09880-Z

13. Wedderburn CJ, Evans C, Yeung S, Gibb DM, Donald KA, Prendergast AJ (2019) Growth and neurodevelopment of HIV-exposed uninfected children: a conceptual framework. Curr HIV/AIDS Rep 16(6):501-513. https://doi.org/10.1007/ s11904-019-00459-0

14. Smith SJ, Zhao XZ, Passos DO, Lyumkis D, Burke TR, Jr, Hughes SH (2021) Integrase strand transfer inhibitors are effective antiHIV drugs. Viruses 13 (2). https://doi.org/10.3390/v13020205

15. Agrawal SM, Lau L, Yong VW (2008) MMPs in the central nervous system: where the good guys go bad. Semin Cell Dev Biol 19(1):42-51. https://doi.org/10.1016/j.semcdb.2007.06.003

16. De Stefano ME, Herrero MT (2017) The multifaceted role of metalloproteinases in physiological and pathological conditions in embryonic and adult brains. Prog Neurobiol 155:36-56. https:// doi.org/10.1016/j.pneurobio.2016.08.002

17. Ethell IM, Ethell DW (2007) Matrix metalloproteinases in brain development and remodeling: synaptic functions and targets. J Neurosci Res 85(13):2813-2823. https://doi.org/10.1002/jnr. 21273

18. Kanda H, Shimamura R, Koizumi-Kitajima M, Okano H (2019) Degradation of extracellular matrix by matrix metalloproteinase 2 is essential for the establishment of the blood-brain barrier in Drosophila. iScience 16:218-229. https://doi.org/10.1016/j.isci. 2019.05.027

19. Loffek S, Schilling O, Franzke CW (2011) Series "matrix metalloproteinases in lung health and disease": biological role of matrix metalloproteinases: a critical balance. Eur Respir J 38(1):191208. https://doi.org/10.1183/09031936.00146510 
20. Page-McCaw A, Ewald AJ, Werb Z (2007) Matrix metalloproteinases and the regulation of tissue remodelling. Nat Rev Mol Cell Biol 8(3):221-233. https://doi.org/10.1038/nrm2125

21. Reinhard SM, Razak K, Ethell IM (2015) A delicate balance: role of MMP-9 in brain development and pathophysiology of neurodevelopmental disorders. Front Cell Neurosci 9:280. https://doi.org/ 10.3389/fncel.2015.00280

22. Rempe RG, Hartz AMS, Bauer B (2016) Matrix metalloproteinases in the brain and blood-brain barrier: versatile breakers and makers. J Cereb Blood Flow Metab 36(9):1481-1507. https://doi. org/10.1177/0271678X16655551

23. Shinotsuka N, Yamaguchi Y, Nakazato K, Matsumoto Y, Mochizuki A, Miura M (2018) Caspases and matrix metalloproteases facilitate collective behavior of non-neural ectoderm after hindbrain neuropore closure. BMC Dev Biol 18(1):17. https://doi.org/ 10.1186/s12861-018-0175-3

24. Small CD, Crawford BD (2016) Matrix metalloproteinases in neural development: a phylogenetically diverse perspective. Neural Regen Res 11(3):357-362. https://doi.org/10.4103/1673-5374. 179030

25. van Hinsbergh VW, Koolwijk P (2008) Endothelial sprouting and angiogenesis: matrix metalloproteinases in the lead. Cardiovasc Res 78(2):203-212. https://doi.org/10.1093/cvr/cvm102

26. Fujioka H, Dairyo Y, Yasunaga K, Emoto K (2012) Neural functions of matrix metalloproteinases: plasticity, neurogenesis, and disease. Biochem Res Int 2012:789083. https://doi.org/10.1155/ 2012/789083

27. Krieger E, Vriend G (2014) YASARA View—molecular graphics for all devices - from smartphones to workstations. Bioinformatics 30(20):2981-2982. https://doi.org/10.1093/bioinformatics/ btu426

28. Harder E, Damm W, Maple J, Wu C, Reboul M, Xiang JY, Wang L, Lupyan D, Dahlgren MK, Knight JL, Kaus JW, Cerutti DS, Krilov G, Jorgensen WL, Abel R, Friesner RA (2016) OPLS3: a force field providing broad coverage of drug-like small molecules and proteins. J Chem Theory Comput 12(1):281-296. https://doi. org/10.1021/acs.jctc.5b00864

29. Sillman B, Bade AN, Dash PK, Bhargavan B, Kocher T, Mathews S, Su H, Kanmogne GD, Poluektova LY, Gorantla S, McMillan J, Gautam N, Alnouti Y, Edagwa B, Gendelman HE (2018) Creation of a long-acting nanoformulated dolutegravir. Nat Commun 9(1):443. https://doi.org/10.1038/s41467-018-02885-x

30. Boska MD, Dash PK, Knibbe J, Epstein AA, Akhter SP, Fields N, High R, Makarov E, Bonasera S, Gelbard HA, Poluektova LY, Gendelman HE, Gorantla S (2014) Associations between brain microstructures, metabolites, and cognitive deficits during chronic HIV-1 infection of humanized mice. Mol Neurodegener 9:58. https://doi.org/10.1186/1750-1326-9-58

31. Wijnen JP, van Asten JJ, Klomp DW, Sjobakk TE, Gribbestad IS, Scheenen TW, Heerschap A (2010) Short echo time 1H MRSI of the human brain at $3 \mathrm{~T}$ with adiabatic slice-selective refocusing pulses; reproducibility and variance in a dual center setting. $\mathbf{J}$ Magn Reson Imaging 31(1):61-70. https://doi.org/10.1002/jmri. 21999

32. Tkac I, Starcuk Z, Choi IY, Gruetter R (1999) In vivo 1H NMR spectroscopy of rat brain at $1 \mathrm{~ms}$ echo time. Magn Reson Med 41(4):649-656. https://doi.org/10.1002/(sici)1522-2594(199904) 41:4\%3c649::aid-mrm2\%3e3.0.co;2-g

33. Dobin A, Davis CA, Schlesinger F, Drenkow J, Zaleski C, Jha S, Batut P, Chaisson M, Gingeras TR (2013) STAR: ultrafast universal RNA-seq aligner. Bioinformatics 29(1):15-21. https://doi. org/10.1093/bioinformatics/bts635

34. Li B, Dewey CN (2011) RSEM: accurate transcript quantification from RNA-Seq data with or without a reference genome. BMC Bioinformatics 12:323. https://doi.org/10.1186/1471-2105-12-323
35. Cheng XC, Fang H, Xu WF (2008) Advances in assays of matrix metalloproteinases (MMPs) and their inhibitors. J Enzyme Inhib Med Chem 23(2):154-167. https://doi.org/10.1080/1475636070 1511292

36. Ren Z, Chen J, Khalil RA (2017) Zymography as a research tool in the study of matrix metalloproteinase inhibitors. Methods Mol Biol 1626:79-102. https://doi.org/10.1007/978-1-4939-7111-4_8

37. Newby AC (2008) Metalloproteinase expression in monocytes and macrophages and its relationship to atherosclerotic plaque instability. Arterioscler Thromb Vasc Biol 28(12):2108-2114. https://doi.org/10.1161/ATVBAHA.108.173898

38. Vandooren J, Knoops S, Aldinucci Buzzo JL, Boon L, Martens E, Opdenakker G, Kolaczkowska E (2017) Differential inhibition of activity, activation and gene expression of MMP-9 in THP-1 cells by azithromycin and minocycline versus bortezomib: a comparative study. PLoS ONE 12(4):e0174853. https://doi.org/10.1371/ journal.pone.0174853

39. Vandenbroucke RE, Libert C (2014) Is there new hope for therapeutic matrix metalloproteinase inhibition? Nat Rev Drug Discov 13(12):904-927. https://doi.org/10.1038/nrd4390

40. Dickinson L, Walimbwa S, Singh Y, Kaboggoza J, Kintu K, Sihlangu M, Coombs JA, Malaba TR, Byamugisha J, Pertinez H, Amara A, Gini J, Else L, Heiberg C, Hodel EM, Reynolds H, Myer L, Waitt C, Khoo S, Lamorde M, Orrell C (2020) Infant exposure to dolutegravir through placental and breastmilk transfer: a population pharmacokinetic analysis of DolPHIN-1. Clin Infect Dis. https://doi.org/10.1093/cid/ciaa1861

41. Kobbe R, Schalkwijk S, Dunay G, Eberhard JM, Schulze-Sturm U, Hollwitz B, Degen O, Teulen M, Colbers A, Burger D (2016) Dolutegravir in breast milk and maternal and infant plasma during breastfeeding. AIDS 30(17):2731-2733. https://doi.org/10.1097/ QAD.0000000000001259

42. Waitt C, Orrell C, Walimbwa S, Singh Y, Kintu K, Simmons B, Kaboggoza J, Sihlangu M, Coombs JA, Malaba T, Byamugisha J, Amara A, Gini J, Else L, Heiburg C, Hodel EM, Reynolds H, Mehta U, Byakika-Kibwika P, Hill A, Myer L, Lamorde M, Khoo S (2019) Safety and pharmacokinetics of dolutegravir in pregnant mothers with HIV infection and their neonates: a randomised trial (DolPHIN-1 study). PLoS Med 16(9):e1002895. https://doi.org/ 10.1371/journal.pmed.1002895

43. Lewis JM, Railton E, Riordan A, Khoo S, Chaponda M (2016) Early experience of dolutegravir pharmacokinetics in pregnancy: high maternal levels and significant foetal exposure with twicedaily dosing. AIDS 30(8):1313-1315. https://doi.org/10.1097/ QAD.0000000000001055

44. Mulligan N, Best BM, Wang J, Capparelli EV, Stek A, Barr E, Buschur SL, Acosta EP, Smith E, Chakhtoura N, Burchett S, Mirochnick M, Team IPP (2018) Dolutegravir pharmacokinetics in pregnant and postpartum women living with HIV. AIDS 32(6):729-737. https://doi.org/10.1097/QAD.0000000000001755

45. Pain JB, Le MP, Caseris M, Amiel C, Lassel L, Charpentier C, Desnoyer A, Farnoux C, Pialoux G, Descamps D, Peytavin G (2015) Pharmacokinetics of dolutegravir in a premature neonate after HIV treatment intensification during pregnancy. Antimicrob Agents Chemother 59(6):3660-3662. https://doi.org/10.1128/ AAC.00173-15

46. van der Galien R, Ter Heine R, Greupink R, Schalkwijk SJ, van Herwaarden AE, Colbers A, Burger DM (2019) Pharmacokinetics of HIV-integrase inhibitors during pregnancy: mechanisms, clinical implications and knowledge gaps. Clin Pharmacokinet 58(3):309-323. https://doi.org/10.1007/s40262-018-0684-z

47. Zash R, Jacobson DL, Diseko M, Mayondi G, Mmalane M, Essex M, Gaolethe T, Petlo C, Lockman S, Holmes LB, Makhema J, Shapiro RL (2018) Comparative safety of dolutegravir-based or efavirenz-based antiretroviral treatment started during pregnancy 
in Botswana: an observational study. Lancet Glob Health 6(7):e804-e810. https://doi.org/10.1016/S2214-109X(18)30218-3

48. Waas ET, Lomme RM, DeGroot J, Wobbes T, Hendriks T (2002) Tissue levels of active matrix metalloproteinase- 2 and -9 in colorectal cancer. Br J Cancer 86(12):1876-1883. https://doi.org/10. 1038/sj.bjc.6600366

49. Dutta S, Sengupta P (2016) Men and mice: relating their ages. Life Sci 152:244-248. https://doi.org/10.1016/j.lfs.2015.10.025

50. United States Environmental Protection Agency (US EPA) (2016) Developmental neurotoxicity study guidance. https://www.epa. gov/pesticide-science-and-assessing-pesticide-risks/developmen tal-neurotoxicity-study-guidance. Accessed December 2018

51. Organisation for Economic Co-operation and Development (OECD) (2007) OECD guidelines for the testing of chemicals. Test no. 426: developmental neurotoxicity study. https://www. oecd-ilibrary.org/environment/test-no-426-developmental-neuro toxicity-study_9789264067394-en. Accessed December 2018

52. Alba-Ferrara LM, de Erausquin GA (2013) What does anisotropy measure? Insights from increased and decreased anisotropy in selective fiber tracts in schizophrenia. Front Integr Neurosci 7:9. https://doi.org/10.3389/fnint.2013.00009

53. Choi JK, Dedeoglu A, Jenkins BG (2007) Application of MRS to mouse models of neurodegenerative illness. NMR Biomed 20(3):216-237. https://doi.org/10.1002/nbm.1145

54. Jung C, Ichesco E, Ratai EM, Gonzalez RG, Burdo T, Loggia ML, Harris RE, Napadow V (2020) Magnetic resonance imaging of neuroinflammation in chronic pain: a role for astrogliosis? Pain 161(7):1555-1564. https://doi.org/10.1097/j.pain.0000000000 001815

55. Miller BL (1991) A review of chemical issues in 1H NMR spectroscopy: N-acetyl-L-aspartate, creatine and choline. NMR Biomed 4(2):47-52. https://doi.org/10.1002/nbm.1940040203

56. Cabrera RM, Souder JP, Steele JW, Yeo L, Tukeman G, Gorelick DA, Finnell RH (2019) The antagonism of folate receptor by dolutegravir: developmental toxicity reduction by supplemental folic acid. AIDS 33(13):1967-1976. https://doi.org/10.1097/QAD. 0000000000002289

57. Chandiwana NC, Chersich M, Venter WF, Akpomiemie G, Hill A, Simmons B, Lockman S, Serenata CM, Fairlie L, Moorhouse MA (2020) Unexpected interactions between dolutegravir and folate: randomised trial evidence from South Africa. AIDS. https://doi. org/10.1097/QAD.0000000000002741

58 Romach EH, Stanislaus D, Zamek-Gliszczynski MJ (2020) Letter to the editor re: Cabrera et al., 2019 'The antagonism of folate receptor by dolutegravir developmental toxicity reduction by supplemental folic acid.' AIDS 34(1):162-163. https://doi.org/ 10.1097/QAD.0000000000002407

59. Zamek-Gliszczynski MJ, Zhang X, Mudunuru J, Du Y, Chen JL, Taskar KS, Huang J, Huang Y, Romach EH (2019) Clinical extrapolation of the effects of dolutegravir and other HIV integrase inhibitors on folate transport pathways. Drug Metab Dispos 47(8):890-898. https://doi.org/10.1124/dmd.119.087635

60. Chopra S, Overall CM, Dufour A (2019) Matrix metalloproteinases in the CNS: interferons get nervous. Cell Mol Life Sci 76(16):3083-3095. https://doi.org/10.1007/s00018-019-03171-9

61. Montenegro-Burke JR, Woldstad CJ, Fang M, Bade AN, McMillan J, Edagwa B, Boska MD, Gendelman HE, Siuzdak G (2019) Nanoformulated antiretroviral therapy attenuates brain metabolic oxidative stress. Mol Neurobiol 56(4):2896-2907. https://doi.org/ 10.1007/s12035-018-1273-8

62. US Food and Drug Administration (FDA) (2021) FDA approves cabenuva and vocabria for the treatment of HIV-1 infection. https://www.fda.gov/drugs/human-immunodeficiency-virus-hiv/ fda-approves-cabenuva-and-vocabria-treatment-hiv-1-infection. Accessed February 27th 2021
63. Overton ET, Richmond G, Rizzardini G, Jaeger H, Orrell C, Nagimova F, Bredeek F, Garcia Deltoro M, Swindells S, AndradeVillanueva JF, Wong A, Khuong-Josses MA, Van Solingen-Ristea R, van Eygen V, Crauwels H, Ford S, Talarico C, Benn P, Wang Y, Hudson KJ, Chounta V, Cutrell A, Patel P, Shaefer M, Margolis DA, Smith KY, Vanveggel S, Spreen W (2021) Long-acting cabotegravir and rilpivirine dosed every 2 months in adults with HIV-1 infection (ATLAS-2M), 48-week results: a randomised, multicentre, open-label, phase 3b, non-inferiority study. Lancet 396(10267):1994-2005. https://doi.org/10.1016/S0140-6736(20) 32666-0

64. Giebeler N, Zigrino P (2016) A disintegrin and metalloprotease (ADAM): historical overview of their functions. Toxins (Basel) 8(4):122. https://doi.org/10.3390/toxins8040122

65. Kelwick R, Desanlis I, Wheeler GN, Edwards DR (2015) The ADAMTS (a disintegrin and metalloproteinase with thrombospondin motifs) family. Genome Biol 16:113. https://doi.org/10. 1186/s13059-015-0676-3

66. Kobayashi M, Yoshinaga T, Seki T, Wakasa-Morimoto C, Brown KW, Ferris R, Foster SA, Hazen RJ, Miki S, Suyama-Kagitani A, Kawauchi-Miki S, Taishi T, Kawasuji T, Johns BA, Underwood MR, Garvey EP, Sato A, Fujiwara T (2011) In vitro antiretroviral properties of S/GSK1349572, a next-generation HIV integrase inhibitor. Antimicrob Agents Chemother 55(2):813-821. https:// doi.org/10.1128/AAC.01209-10

67. Pereira GFM, Kim A, Jalil EM, Fernandes Fonseca F, Shepherd BE, Veloso VG, Rick F, Ribeiro R, Pimenta MC, Beber A, Correa RG, Lima R, Maruri F, McGowan CC, Schwartz Benzaken A, Grinsztejn B, Castilho JL, National Cohort Study of D, Pregnancy Outcomes in B (2021) Dolutegravir and pregnancy outcomes in women on antiretroviral therapy in Brazil: a retrospective national cohort study. Lancet HIV 8(1):e33-e41. https://doi.org/10.1016/ S2352-3018(20)30268-X

68. Amusan P, Power C, Gill MJ, Gomez D, Johnson E, Rubin LH, Fujiwara E (2020) Lifetime antiretroviral exposure and neurocognitive impairment in HIV. J Neurovirol 26(5):743-753. https://doi. org/10.1007/s13365-020-00870-z

69. Yombi JC (2018) Dolutegravir neuropsychiatric adverse events: specific drug effect or class effect. AIDS Rev 20(1):14-26

70. Bourgi K, Rebeiro PF, Turner M, Castilho JL, Hulgan T, Raffanti SP, Koethe JR, Sterling TR (2020) Greater weight gain in treatment-naive persons starting dolutegravir-based antiretroviral therapy. Clin Infect Dis 70(7):1267-1274. https://doi.org/10.1093/ $\mathrm{cid} / \mathrm{ciz} 407$

71. Caniglia EC, Shapiro R, Diseko M, Wylie BJ, Zera C, Davey S, Isaacson A, Mayondi G, Mabuta J, Luckett R, Makhema J, Mmalane M, Lockman S, Zash R (2020) Weight gain during pregnancy among women initiating dolutegravir in Botswana. EClinicalMedicine 29-30:100615. https://doi.org/10.1016/j.eclinm.2020. 100615

72. Group NAS, Kouanfack C, Mpoudi-Etame M, Omgba Bassega P, Eymard-Duvernay S, Leroy S, Boyer S, Peeters M, Calmy A, Delaporte E (2019) Dolutegravir-based or low-dose efavirenz-based regimen for the treatment of HIV-1. N Engl J Med 381(9):816-826. https://doi.org/10.1056/NEJMoa1904340

73. Venter WDF, Moorhouse M, Sokhela S, Fairlie L, Mashabane N, Masenya M, Serenata C, Akpomiemie G, Qavi A, Chandiwana $\mathrm{N}$, Norris S, Chersich M, Clayden P, Abrams E, Arulappan N, Vos A, McCann K, Simmons B, Hill A (2019) Dolutegravir plus two different prodrugs of tenofovir to treat HIV. N Engl J Med 381(9):803-815. https://doi.org/10.1056/NEJMoa1902824

74. Beroun A, Mitra S, Michaluk P, Pijet B, Stefaniuk M, Kaczmarek L (2019) MMPs in learning and memory and neuropsychiatric disorders. Cell Mol Life Sci 76(16):3207-3228. https://doi.org/ 10.1007/s00018-019-03180-8 
75. Gorwood J, Bourgeois C, Pourcher V, Pourcher G, Charlotte F, Mantecon M, Rose C, Morichon R, Atlan M, Le Grand R, Desjardins D, Katlama C, Feve B, Lambotte O, Capeau J, Bereziat V, Lagathu C (2020) The integrase inhibitors dolutegravir and raltegravir exert pro-adipogenic and profibrotic effects and induce insulin resistance in human/simian adipose tissue and human adipocytes. Clin Infect Dis. https://doi.org/10.1093/cid/ciaa259

76. Jaoude J, Koh Y (2016) Matrix metalloproteinases in exercise and obesity. Vasc Health Risk Manag 12:287-295. https://doi.org/10. 2147/VHRM.S103877

77. Li X, Zhao Y, Chen C, Yang L, Lee HH, Wang Z, Zhang N, Kolonin MG, An Z, Ge X, Scherer PE, Sun K (2020) Critical role of matrix metalloproteinase 14 in adipose tissue remodeling during obesity. Mol Cell Biol 40 (8). https://doi.org/10.1128/MCB. 00564-19

78. Ruiz-Ojeda FJ, Mendez-Gutierrez A, Aguilera CM, Plaza-Diaz J (2019) Extracellular matrix remodeling of adipose tissue in obesity and metabolic diseases. Int J Mol Sci 20 (19). https://doi.org/ 10.3390/ijms20194888

79. Lafleur MA, Handsley MM, Edwards DR (2003) Metalloproteinases and their inhibitors in angiogenesis. Expert Rev Mol Med 5(23):1-39. https://doi.org/10.1017/S1462399403006628
80. Raffetto JD, Khalil RA (2008) Matrix metalloproteinases and their inhibitors in vascular remodeling and vascular disease. Biochem Pharmacol 75(2):346-359. https://doi.org/10.1016/j.bcp.2007.07. 004

81. The Lancet H (2020) End resistance to dolutegravir roll-out. Lancet HIV 7(9):e593. https://doi.org/10.1016/S2352-3018(20) 30231-9

82. World Health Organization (2018) Dolutegravir (DTG) and the fixed dose combination (FDC) of tenofovir/lamivudine/dolutegravir (TLD): Briefing note. http://www.who.int/hiv/pub/arv/DTGTLD-arv_briefing_2018.pdf

83. The Joint United Nations Programme on HIV/AIDS (UNAIDS) (2019) Global HIV \& AIDS statistics-2020

84. The Lancet H (2019) A lesson to learn from dolutegravir roll-out. Lancet HIV 6(9):e559. https://doi.org/10.1016/S2352-3018(19) 30270-X

Publisher's Note Springer Nature remains neutral with regard to jurisdictional claims in published maps and institutional affiliations. 